\title{
CENTRO Y ÁREAS LATERALES: LA FORMACIÓN DEL CELTIBÉRICO SOBRE EL FONDO DEL CELTA PENINSULAR HISPANO ${ }^{1}$
}

\author{
Patrizia de Bernardo Stempel
}

\section{Lengua(s) Céltica(s) en la Península Ibérica}

A) La evidencia histórica. Que la Península Ibérica en la antigüedad hospedó a gentes de habla céltica no sólo en el territorio de la antigua Celtiberia es archisabido. Además de los grupos de población que segura o posiblemente constituían la Celtiberia propiamente dicha, Estrabón y sus fuentes más antiguas nos dicen que había Celtas en la mayor parte de la península y que en particular los $K \in \lambda$ toú que vivían cerca del río

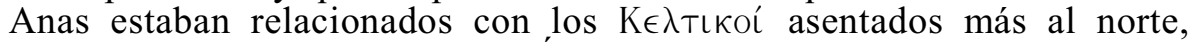
cerca de los - también celtas- Ártabros en el extremo noroeste (Geogr. $3,1,6 ; 3,3,5)$.

De particular interés resultará para nuestro asunto la observación de

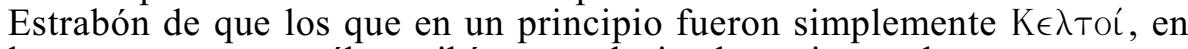
los momentos que él escribía - es decir al comienzo de nuestra erahabían pasado a llamarse $K \in \lambda \tau i ́ \beta \eta \rho \in S$ y Bń $\omega \omega \nu \in S^{2} .^{2}$

B) El corpus lingüístico. En concreto, la documentación escrita del celta hispano la constituyen

1 El artículo -escrito durante mi estancia del curso 2000-01 como Visiting Fellow del
Department of Welsh de la University of Wales Aberystwyth gracias a una dotación del
Leverhulme Trust - refleja las conclusiones de la ponencia leída el 27 de julio de 2000 bajo
el título "Las lenguas célticas en la Península Ibérica" en el marco de un curso de verano de
arqueología de la Fundación Duques de Soria. Agradezco la invitación a los organizadores G.
Ruiz Zapatero y A. Jimeno Martínez y a todos los colegas participantes, entre ellos a los
arqueólogos José Luis Maya, de quien lamentamos la tan prematura pérdida, y J. A. Arenas
Esteban una discusión muy estimulante. En particular recuerdo la exhortación de este último a
asumir "una actitud menos acrítica a la hora de equiparar a Celtas y Celtíberos" (Arenas
Esteban [1998/99a], p. 9), y espero que mi contribución constituya también un aporte en este
sentido. A M M Cruz González Rodríguez, Joaquín Gorrochategui y José Ma $M^{a}$ Vallejo van mis
más sentidas gracias por la revisión del texto y unos comentarios.

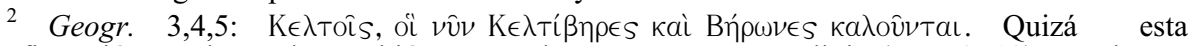
afirmación pueda ayudar también a entender correctamente a Plinio (N.H. 3, 13) cuando nos dice que los Celticos, qui Lusitaniam attingunt [...] a Celtiberis ex Lusitania advenisse manifestum est sacris, lingua, oppidorum vocabulis [...] (de otra forma: Villar [1999], p. 64). 
1) leyendas monetales e inscripciones en signario epicórico y lengua céltica procedentes de la Celtiberia;

2) inscripciones en alfabeto latino y lengua céltica procedentes de la Celtiberia;

3) nombres célticos contenidos en inscripciones ibéricas: ${ }^{3} \mathrm{cf}$. para los antropónimos Correa (1993), a cuyo katulatie- $n^{4}$ se pueden añadir más al sur, entre otros, las formas SeKenius y SelKinius ( $\leftarrow$ célt. *Selg-in-io-s 'cazador', cf. los británicos $\Sigma \in \lambda$ yoova $)$ en F.9.5 y F. 9.7, la agrupación de los Abilicorum, o sea el nom. pl. *Abilicōs, en $\mathrm{A} \beta \iota \lambda \iota \kappa \in \rho$ (G. 1.7), ${ }^{5}$ y el probable teóforo Belenos en E.1.318 y E.1.319, ${ }^{6}$ mientras que "la intrusión de una deidad céltica en ámbito ibérico" está documentada por Neitin en Huesca.

Dignos de notar son además los posibles híbridos iltuRATIN en el sello E.1.1, el iltiRATIN que aparece -igual que bo.ti.l.ko.s, BODILCOS, nombre céltico de magistrado - como una de las leyendas complementarias en las monedas de Obulco, al este de Córdoba (hoy en día Porcuna / Jaén: A.100-12 y resp. 10, 11, 17), donde el céltico ratin estaría especificado por su equivalente ibérico iltu, al cual se atribuye "el significado aproximado de "ciudad", según el tipo muy frecuente de topónimos compuestos

\footnotetext{
${ }^{3}$ En inscripciones ibéricas se atestiguan también los primeros nombres célticos en territorio galo, cf. de Hoz (1997/99), p. 219: "le témoignage gaulois le plus ancien que je connaisse dans la zone est constitué par un bol attique de vernis noir d'Ensérune avec une inscription osiobarenYi (MLH B.1.59) [...] qui semble contenir un NP gaulois, Oxiobarros ou Oxiomaros. Le support est semble-t-il daté de 320-325”. Aún más antiguo sería el bikilako que aparece en Ensérune como primer propietario de una pátera datada en torno a 375/350 a.C. (Die Iberer, $n^{\circ} 90$, p. 284) si representara el gen.sing. céltico antiguo /brigilako/ de un NInd *Brigilākos paralelo al célt. *Seg-il-ākos.

Como advierte de Hoz (1991/92), p. 231, "it is necessary [...] to study carefully the date of Iberian inscriptions with Celtic PNN", en unos casos incluso reconsiderando la datación de los soportes (l.c. nota 72).

${ }^{4}$ Aparecido en Ampurias (1.c. p. 116) sobre un plomo de c. 200 a.C. "perteneciente o relativo a Katulatios": de Hoz (1996/97), pp.61s. Los otros nombres personales estudiados por Correa (1993), pp. 103ss., proceden en su mayoría del territorio ibérico más septentrional y pertenecen a diferentes tipos morfológicos, cf. compuestos como diuiś, lituriś y eśkinge, katubare junto a derivados como kanio y kasike, anaioś / anaie, gabirilo, alauca. Hay que reseñar, al margen, que en estos nombres célticos en contexto ibérico "s representa casi siempre la africada dental gala" (Correa [1993], p. 105, con ejj. como asedile / asetil y tesile), lo que parece confirmar una de las tres fuentes etimológicas del cib. $\boldsymbol{s} / \mathbf{z} /$ postuladas por DBSt $1999 / 01$, p. 330 y n. 88 .

${ }^{5}$ No obstante el "Kein Anschluß” de Untermann (MLH III/2 pp. 289s.); cf. idem en Beltrán et al. (1996), pp. 121s.

${ }^{6}$ Nótese que Untermann (MLH III/2 1.c.) se muestra reacio a aceptar la presencia de algo céltico, pero sin sustituir una hipótesis hermenéutica igualmente satisfactoria, e incluso enmendando los hallazgos hasta obtener un ibérico **belennes "Am nächsten vergleichbar [...], zusammengesetzt aus beles und -nes [...]. nos ist allerdings sonst nicht als PN.-Element nachweisbar".

${ }^{7}$ Marco Simón (1994), p. 41.

${ }^{8}$ En las palabras de Velaza Frías (1996), p. 54.
} 
originados de la traducción de una lengua a otra, como en el siciliano Linguaglossa ${ }^{9}$

4) nombres célticos contenidos en inscripciones en lengua "tartesia"; 10

5) nombres célticos (sobre todo teónimos ${ }^{11}$ ) en inscripciones en lengua lusitana $\mathrm{y}$ en inscripciones latinas procedentes de Lusitania; ${ }^{12}$

${ }^{9}$ Se trata en este caso de una leyenda que se ha interpretado hasta ahora tradicionalmente como nombre personal (cf. MLH I/1, p. 337 con bibliografía), y que, sin embargo, parece confirmar, una vez más, las estrechas relaciones culturales existentes entre celtíberos e iberos (en favor de su valorización cf. Arenas Esteban [1998/99b], pp. 200ss.). Recuérdese que probablemente "el ibérico no fue la lengua coloquial y cotidiana" de la extensa región donde se halla, sino que más bien alcanzó su máxima extensión territorial desde un núcleo originario suroriental como "lengua vehicular y de prestigio", "de formas diversas y con intensidad diferente": así de Hoz, p.ej. (1995b), p. 283, en particular "podemos afirmar que la región contestana, más o menos la actual provincia de Alicante, formaba parte del núcleo propiamente ibérico"; cf. también de Hoz (1993), pp. 22s., y ahora Almagro-Gorbea en Almagro et al. (2001), p. 330, donde no obstante J. de Hoz no aparece en la bibliografía.

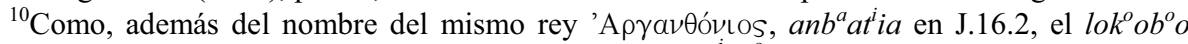
( $\left(\right.$ Logobo/?) de la piedra de Bensafrim (J.1.1, 1. 1), $t^{i}$ irt ${ }^{\circ}$ os (i/Tritos/?) en J.1.2, 1.2 o el posible genitivo plural liirnest ${ }^{a} a k^{u} u n$ en J.19.1; v. la recapitulación de Untermann en MLH IV, pp. 166-168. Si, pese a la scriptio continua y a los problemas de interpretación que quedan, el análisis de J.A. Correa es correcto —cf. su valoración global (1994/96), p. 73—, la presencia de estos nombres se puede entender mejor teniendo en cuenta que "en las partes occidental y septentrional del área tartésica aparecen topónimos hispano-celtas" (Untermann [2000], p. 69). Además, según Almagro Gorbea en Almagro et al. (2001), pp. 334s., "en las regiones mineras de Huelva se conoce, desde el siglo VI a.C., la penetración de grupos que por sus características culturales podrían considerarse relacionables con las gentes de estirpe céltica que están documentadas por referencias históricas en tiempos posteriores y que ocuparon amplios territorios del suroeste peninsular y de la Andalucía occidental, predominantemente en las zonas montañosas del área tartésica originaria". Lo que sin embargo no parece verosímil es que pueda tratarse de gente que ya hablase el celta del $4^{\circ}$ periodo (v. la terminología en la nota 39), como supone, no obstante, Villar (1999), pp. 66s. y 74, cuando nos habla de "incursiones de galos en la Península Ibérica [...] que podría(n) haber comenzado hacia el s. VI a. C., o acaso algo antes".

${ }^{11}$ P.ej. Iccona, una diosa Salus local que aparece en la inscripción en lengua lusitana de Cabeço das Frágoas, "von derselben Basis abgeleitet, die air. icc 'gesund' [...] fortsetzt" (cf. la discusión en DBSt, ZCP 53). Es también probable que el nombre de la divinidad Banduis < * $b^{h} n d^{h} u-i-s$ 'dios del enlace, de la conexión' sea lingüísticamente céltico (a corregir sin embargo Martín Bravo [1999], p. 253, porque en lusitano, como se comenta en la nota siguiente, esperaríamos $* * F e / a n \theta u$-); además del desarrollo de las sonoras aspiradas y de la sonante nasal, la formación de la palabra e incluso la desaparición de la $-w$ - detrás de dos consonantes que se aprecia — según Pedrero (1997/99), p. 538 - en la provincia de Lusitania frente a la Gallaecia antigua, es decir, en los hallazgos del área que resulta ser dialectalmente más modernizada, corresponden a patrones célticos: cf. hispano-célt. Mantua : Manta, Mantaus y el desarrollo célt. -CCwV- > -CCV- (respectivamente Albertos Firmat [1974-76], p. 82, y NWÄI, pp. 218s.). Se trata del mismo fenómeno que se puede apreciar en el NL DEsSobriga 'Fortaleza del Sur (?)' (: air. dess 'dexter; right; south'; cf. NWÄI, pp. 212s., y Albertos Firmat [1990], p. $136 \mathrm{~N}^{\circ}$ 38) frente al más conservador cib. DESSUAeona (K.14.2); a corregir por lo tanto Solana Sainz (1991), p. 37, y MLH V/1, p. 99.

${ }^{12}$ Dado que muchos de estos teónimos se hallan también más al norte en territorio galaico (cf. el mapa 4 en MLH IV, p. 436), se ha hablado al respecto de teonimia occidental ("cultural changes did not take place so quickly [...] in western [...] regions of Hispania [...]. During the 1 st and 2nd centuries and even later, native personal names and theonyms appear frequently in inscriptions, local family structures or institutions continue", F. Beltrán Lloris [1999], p. 135). Pero a diferencia de muchos de los nombres atestiguados en su territorio o incluso a 
6) nombres célticos - de varios tipos y cronología- en inscripciones latinas procedentes de cualquiera de las áreas geográficas de la Península Ibérica; ${ }^{13}$

7) topónimos célticos atestiguados por fuentes clásicas. ${ }^{14}$

C) El término "hispano-celta" y sus diferentes aplicaciones. Mientras que el corpus de las categorías (1) y (2) se clasifica unánimamente como "celtibérico" (con un término acuñado por Tovar, quien fue el primero en demostrar su celticidad en los años cuarenta del último siglo) ${ }_{15}$ se suele fechar entre el siglo II a.C. y el comienzo de nuestra era, ${ }^{5}$ algunos autores defienden la necesidad de distinguir el corpus celtibérico, es decir la lengua de los textos epicóricos provenientes de la antigua Celtiberia, del material, básicamente onomástico y más tardío, que procede del conjunto de la Península (sobre todo las categorías 6-7); así de Hoz (1986/88) adopta el término "Hispano-Celtic" específicamente para este último grupo,${ }^{10}$ mientras que su acuñador, D.E. Evans, comprendía en él los dos corpora

través de ella, la lengua lusitana no puede considerarse céltica por toda una serie de isoglosas que no coinciden y que en algunos casos son incluso incompatibles con las del grupo lingüístico celta (como el desarrollo fricativo de las sonoras aspiradas indoeuropeas), sino más bien de tipo aparentemente itálico; cf. Schmidt (1980/85) y Gorrochategui (1985/87). Otra bibliografía en Meid (2000), pp. 3s.

13 "wenn auch die sprachliche Zuordnung und etymologische Deutung solcher Namen oft diskutabel war und immer noch ist ", Meid (2000), p. 1. Los nombres personales como Celtius, evidentemente, se hallan en territorios donde la mayoría de los habitantes no eran de habla céltica, y en particular "los antropónimos de tipo étnico como Celtiber/-a [...] contribuyen a definir por exclusión el área propiamente celtibérica" y además "ponen de relieve las zonas de emigración de los Celtíberos", Ruiz Zapatero y Lorrio (1998/99), p. 22.

${ }^{14}$ Así la Segestica mencionada por Livio "en la zona catalana, de claro celtismo lingüístico", Marco Simón (1996), p. 53 (v. más adelante al § VII/2). El tamaño y la tipología de los diferentes oppida de la Hispania "Céltica" son analizados por Almagro-Gorbea y Dávila (1995), quienes distinguen tres áreas, la más antigua al sur, "más próxima al mundo turdetano e ibérico" y con "un urbanismo concentrado y denso", y la más reciente en la Hispania "húmeda" con oppida tardíos y de escaso tamaño, mientras que los oppida más extensos, de finales del III y II siglo se encuentran entre las dos (p. 215).

${ }^{15}$ Es decir que el período de su transmisión escrita correspondería a las fases que los arqueólogos llaman de "Celtibérico tardío" y de "Celtíbero-romano" ("Paradoxically, it is in the phase of early Romanization - and [...] due to it - that texts produced by the native peoples of this area appear for the first time and over a period of barely two centuries", F. Beltrán Lloris [1999], p. 137): cf. p.ej. la "Síntesis de la periodización del Bronce final y la Edad del Hierro en el sector central del Sistema Ibérico" en Arenas Esteban (1998/99b), p. 193, que propone un período "¿Protoceltibérico?” desde el 700 a.C. al comienzo del "Celtibérico antiguo" hacia el 600 a.C., haciendo empezar el "Celtibérico pleno" en el 1er cuarto del siglo V a.C.; cf. también Ruiz Zapatero \& Lorrio (1998/99), pp. 23s., y Lorrio, por último (2001), p. 185.

16 “ $[. .$.$] we must distinguish clearly between the Celtiberian language, known by the scarce$ but nevertheless authentic Celtiberian texts written by Celtiberian speakers, and the other languages known to us only under Roman dominion by onomastic materials grafted on the Latin inscriptions, and written in the Latin alphabet by speakers of Latin.” (p. 196). Cf. también idem (1996/97), p. 57: "podemos utilizar la denominación de hispano-celta para un conjunto de datos lingüísticos célticos atestiguados en la Península Ibérica, pero de los que no nos consta con certeza que sean específicamente celtibéricos". 
indistintamente ${ }^{17}$ y Villar (1999), p. 74, llega incluso a considerar los dos términos como "estrictamente equivalentes".

En otro importante artículo de Hoz (1991/92), p. 232, habla de "various forms of Proto-Hispano-Celtic" para referirse al conjunto de los corpora 1-7. Sin embargo -además de distinguir entre los corpora celtibérico e hispano-celta stricto sensu- es necesario disponer de un tercer término para denominar cualquier tipo de celta como entidad lingüística atestiguada en la Península Ibérica, pero, para evitar ambigüedades, proponemos utilizar como tercera etiqueta la formulación "celta (peninsular) hispano" ("celtique hispanique", "Hispania's Celtic", "das Keltische Hispaniens") para cuando no estén implícitas distinciones espacio-temporales como las que nos llevan a hablar de "(lengua y corpus) celtibérico" y de "(corpus) hispano-celta".

\section{LAS EXPLICACIONES PROPUESTAS}

Aunque la evidencia lingüística muestra que el celta, en varias formas, fue hablado en amplias áreas de Iberia, podríamos decir con Cunliffe $\left({ }^{2} 1999\right)$, p. 138 , que hasta ahora ni cuenta con una cronología concreta ni puede ser utilizado como modelo para el movimiento de población. ${ }^{18}$ Las explicaciones propuestas, más o menos explícita o incluso conscientemente, se pueden clasificar de la siguiente manera:

A) ¿El celtibérico, origen del hispano-celta? Es decir el celtibérico visualizado como el celta más antiguo llegado a Hispania, ${ }^{19}$ desde el cual procedería cualquier otro testimonio peninsular más tardío, una simplificación implícita hasta ahora en todos los árboles genealógicos propuestos para la rama lingüística céltica, que sólo mencionan el celtibérico. ${ }^{20}$

\footnotetext{
${ }^{17}$ Sobre la historia de la cuestión cf. Schmidt (1999/01), p. 599. Nótese que el hispano-celta propiamente dicho no juega sino un papel puramente ocasional en los MLH, mientras que Untermann, p.ej. (2001), p. 8, utiliza el término para indicar el grupo lingüístico que él cree poder reconstruir como etapa anterior al lusitano y al celtibérico.

${ }^{18}$ Cf. también al mismo Almagro-Gorbea (2001), p. 95: "se suelen considerar originarios de Europa Central, pero no se conoce bien su proceso formativo y aún menos cómo y cuándo llegaron a la Península Ibérica, donde ocupaban amplias áreas del centro y del occidente."

${ }^{19}$ Así p.ej. se habla de "los c eltíb e r o s que hablan una lengua pa le o c e l t a", del "proceso de penetración de gentes de Europa en la península y de los celtíberos en concreto" o de "la celtización de las comunidades vettonas [...] bajo la presión del mundo celtibérico" (respectivamente Untermann [2000], p. 73; Gorrochategui [1994], p. 17; Álvarez-Sanchís [1999], p. 319, en la tradición que fue entre otros de Tovar: "Clearly Celtic [...], were the Celtiberians in a strict sense", [1951], p. 12; los espaciados son míos). Nótese también el uso del término "celtíberos" en pasajes como el siguiente: "aunque no tenemos la completa certeza de si existieron grupos étnicos que se reconocieron como celtíberos en momentos previos a la configuración de la Celtiberia [...], resulta evidente que esos 'celtíberos antiguos' [...] constituyen sin duda su precedente inmediato." (Lorrio [2001], p. 186).

20 "la única [scil. lengua celta] que sin ningún género de duda ha sido identificada como tal en la Península Ibérica”: Ruiz Zapatero y Lorrio (1998/99), p. 26. Más rotundamente que otros, Villar (1999), p. 74, afirma ahora que "el único dialecto celta autóctono de Hispania que por el momento podemos detectar es el celtibérico". Una rama celtibérica única e independiente es esbozada también por C. Watkins (1999) en su forzado intento de reformar el árbol tradicional, a pesar de sus dudas sobre si el celtibérico sea una rama separada del celta por
} 
Por lo que concierne a su llegada hay que decir que, si, por un lado, los arqueólogos rechazan actualmente "el modelo de Schüle (1969) que explicaba, con las teorías entonces en boga, la aparición de las culturas del Hierro de la Meseta como resultado de la llegada de jinetes procedentes de Centroeuropa", ${ }^{21}$ por otro, pese a todas las modas actuales $^{22}$ no se puede pensar que en una sociedad todavía prevalentemente ágrafa una lengua pudiese transmitirse sin hablantes sino simplemente por medio de los objetos intercambiados (no había entonces folletos explicativos...).

B) ¿"Cumulative Celticity"? El término, utilizado originariamente por Hawkes (1971/73) para explicar la celtización de las Islas Británicas, se podría aprovechar también - y de hecho ocasionalmente ha sido aprovechado en este sentido- para indicar las diferentes capas de celtohablantes (es decir de celtas que conservaban la labiovelar sorda - como los celtíberos-, a los cuales se superpusieron unos más modernos " $p$-celtas"), distinguidas ya por Pokorny (1936-1940) en el material lingüístico peninsular.

Pero aunque es cierto que la suposición de sendas "oleadas" es lingüísticamente verosímil y que de hecho hubo unas infiltraciones de galohablantes en época histórica (v. más adelante bajo el apartado IV), no hay evidencia material de invasiones dobles o múltiples que apoye el modelo arqueológico desarrollado por Bosch-Gimpera desde el 1918: "Esta teoría explicativa [...], hábil y cuidadosamente trabajada, que tenía su punto débil [...] en la escasez de excavaciones a disposición, tuvo una general aceptación ${ }^{23}$ hasta que nuevas excavaciones y nuevos materiales ofrecieron un panorama diferente". ${ }^{24}$

C) ¿Desarrollo desde un "precelta”? Que el celta peninsular y específicamente el celtibérico se haya desarrollado en la Hispania misma como resultado de un estrato precéltico (unos hablan incluso de un "substrato "protocéltico",25) es una teoría que, propuesta por algunos arqueólogos sin tener suficientemente en cuenta los datos y los

filiación genética (op. cit., p. 539). Una excepción sólo aparente constituye Eska (1994), p. 14, que habla exclusivamente de hispano-celta, pero únicamente por seguir el planteamiento de Evans explicado arriba en el § I (c).

${ }^{21}$ Así Ruiz Zapatero y Lorrio (1998/99), p. 32.

${ }^{22}$ Rechazadas también por de Hoz, p.ej. (1992), p. 3, se pueden resumir con las palabras de Cunliffe ( $\left.{ }^{2} 1999\right)$, p. 139: "Invasionist theories are rejected in favour of a model based on the assimilation of selected cultural elements by the indigenous élites".

${ }^{23}$ Aunque ya en (1950), p. 12, Tovar advertía que era "too early to take a position on the point”. Una visión de conjunto ofrecen Bosch Gimpera $1945\left(={ }^{2} 1995\right)$ y sus artículos (19501956).

${ }^{24}$ Sayas \& Lopez (1991), p. 82. Totalmente escéptica es Kalb (1990) que en su detallado resumen de las explicaciones arqueológicas propuestas para los celtas hispanos pone en duda incluso "die Basis der ethnischen Deutung derjenigen archäologischen Hinterlassenschaften in Frage, die seit Bosch-Gimpera/Kraft und Almagro [Basch] für die hispanischen Kelten in Anspruch genommen werden".

${ }^{25}$ Así Almagro Gorbea (2001), p. 100. 
mecanismos de la lingüística, lamentablemente se ha puesto de moda en el último decenio. ${ }^{26}$

A este respecto hay que aclarar las siguientes equivocaciones lingüísticas: ${ }^{27}$

1) el correcto uso del término 'sustrato' hace referencia a una capa lingüística anterior a otra y ya prácticamente desaparecida, o sea que sólo se hablaría correctamente de 'sustrato PREcéltico' (para una capa lingüística genéticamente no céltica) y respectivamente de 'estrato PROTOcelta' (para una fase lingüística aunque arcaica ya genéticamente céltica, o sea evolucionada desde el celta común);

2) el término "Alteuropäisch" (= Antiguo Europeo) se refiere sóla y únicamente a un tipo particular de onomástica indoeuropea o incluso indoeuropeizada y no constituye de ninguna forma un nudo intermedio en el desarrollo desde el indoeuropeo a las lenguas individuales; ${ }^{28}$

3) afirmar que la lengua lusitana podría pertenecer a una capa de indoeuropeo precedente al celta, o sea llegada a la Península Ibérica anteriormente al celta, no significa que dicha lengua sea por eso "protocéltica": de hecho el celta hispano no puede haberse desarrollado desde el lusitano ${ }^{29}$ más que hubiera podido hacerlo desde el germánico o el griego...

4) Si además se habla de un estrato "PROTOcéltico" en la Península Ibérica (v. la n. 25), evidentemente estos celtas tendrán que haber llegado desde algún otro sitio.

5) Si por el contrario se está hablando en realidad de un "sustrato PREcéltico", 30 las coincidencias lingüísticas existentes entre el celta hispano y las otras lenguas célticas son tantas y de tanto peso que impiden poder ser atribuidas a una simple casualidad, es decir haberse desarrollado independientemente en diferentes sitios. Este hecho constituye un obstáculo insuperable para toda teoría de este tipo.

Nótese, sin embargo, que la "llegada de [...] elites guerreras originarias del mundo céltico extrapirenaico" vuelve a ser parte integrante también de esta misma teoría en sus más recientes presentaciones por Almagro Gorbea. ${ }^{31}$

\footnotetext{
${ }^{26}$ Cf. primero Almagro Gorbea, p.ej. (1991) y (1993), y después otros como Lorrio (1997), pp. 371s. y (2001), p. 187, Peralta Labrador (2000), pp. 39s. etc.

${ }_{27}$ Otras dificultades de tipo arqueológico han sido expresadas por Burillo (1998), pp. 109s. y Arenas Esteban (1998/99b), pp. 195s.

${ }^{28}$ Por lo tanto el "antiguo europeo" no podría ser una fase preliminar del celta hispano como sugiere p.ej. Peralta Labrador (2000), p. 37, y aparentemente también Ruiz Zapatero (1995), p. 101 .

${ }^{29}$ Como propone p.ej. Peralta Labrador (2000), p. 39.

${ }^{30}$ Así claramente Almagro Gorbea en Almagro et al. (2001), p. 365.

31 "impuestas inicialmente como grupo dominante" y "contemporáne[a]s o ligeramente anteriores" a las primeras manifestaciones de la cultura celtibérica: Almagro et al. (2001), p. 365; de forma más explícita idem (2001), p. 102: "sólo la llegada de nuevas gentes parece poder explicar la aparición de la lengua celtibérica, que [...] habría que relacionar con gentes lejanamente vinculadas con los celto-ligures, dado el común origen de los Campos de Urnas del sur de Francia y del noreste de la Península Ibérica”.
} 
D) ¿El celtibérico como desarrollo parcial de un celta más arcaico existente en la Península? Este escenario, parecido en el fondo al "dialecto celta cuya evolución, incorporando quizá elementos locales diversos pero conservando el esqueleto básico de su gramática heredada, daría lugar más adelante al celtibérico de las inscripciones conocidas" planteado por de $\mathrm{Hoz}^{32}$ es compatible con las investigaciones arqueológicas más recientes, conciliando la suposición de una capa de celta antiguo con la reivindicación de "la importancia de corrientes culturales alternativas a la 'céltica' en la configuración del mundo celtibérico arcaico". ${ }^{33}$ mente: ${ }^{34}$

Entre las posibilidades arqueológicas a elegir tenemos actual-

a) la "reliance on an Atlantic Bronze Age 'protoCeltic' culture", 35 que puede resultar problemática si pensamos que "los indoeuropeos de finales del II milenio a.C. todavía no eran celtas, y son demasiadas las similitudes que en el siglo II a.C. mantienen los 'celtas peninsulares' con los del resto de Europa como para admitir que ambas manifestaciones procedan de un sustrato protocéltico común tan remoto"; 36

\footnotetext{
32 (1995), p. 272, aunque él lo visualice todavía como "un componente lingüístico protoceltibérico" (el espaciado es mío); "tenemos amplios indicios de grupos célticos fuera y lejos del territorio celtibérico, sin que estemos en condiciones de determinar si su lengua era o no el celtibérico", "However, it is not necessary to think that all the Celtici were related to the Celtiberians, and at all events we know that there were Celts in the Iberian Peninsula that should not be confused with Celtiberians" (de Hoz respectivamente [1994], p. 351, y [1992], p. 10). En la posible coexistencia de sendas lenguas célticas en la Península Ibérica piensan también García Alonso (1999/00), p. 32, Luján (1999/00), p. 56, Prósper (en prensa), y Gorrochategui (2001), p. 207, aunque sin establecer relaciones jerárquicas. Con respecto a la lápida cántabra K.26.1 de Iuliobriga, fundación que parece haber continuado la antigua Brigantia, es, sin embargo, preciso añadir a la discusión en Gorrochategui loc.cit. que la segmentación anterior a la de DBSt en (2000 [2002]) (Jlicui Amig() monimam) va en contra de la sintaxis observable en las otras inscripciones con el mismo formulario $y$, reducible básicamente a \{Dat. de NP + monimam\}, careciendo así de verosimilitud.

${ }^{33}$ Arenas (1998/99b), p. 207; cf. también idem (1998/99a), p. 8, en defensa del "importante papel que los influjos mediterráneos tuvieron en aquel proceso" y Cunliffe $\left({ }^{2} 1999\right)$, p. 139s. Lingüísticamente, la multiculturalidad de la sociedad celtibérica se trasparenta en los nombres ibéricos y quizá también griegos y latinos que se encuentran en el listado de más de doscientas personas del tercer bronce de Botorrita (cf. Meid [2000], p. 9 vs. F. Beltrán Lloris [1999], p. 145), así como en el carácter muchas veces no céltico de su toponimia (García Alonso, p.ej. [1999/00], p. 41); v. también el mismo Beltrán (1999), pp. 141ss., sobre dos "Iberian inscription(s) in a Roman house inhabited by Celtiberians" y los préstamos silabur y tiaso (gen.sg.).

${ }^{34}$ Es interesante observar que, según Grünewald (2000), pp. 379s., ya las fuentes antiguas discuten si los "Einwanderer (a) sich als eine große, nach außen zunächst relativ geschlossene Gruppe auf der iberischen Halbinsel niedergelassen haben (so bereits Strabo 3,4,5 p.158. Lucan. 4,8ff.) oder (b) als eine relativ kleine Gruppe die einheimische, zahlenmäßig weit überlegene Bevölkerung unterworfen und keltisiert haben (App. Ib. 2,5)."

En favor de "pequeños grupos [porque] pueden pasar por un país extranjero sin dejar la huella de su marcha y de sus estaciones intermedias" Untermann (1991/95), pp. 18ss.

${ }^{35}$ En palabras de Cunliffe ( $\left.{ }^{2} 1999\right)$, p. 139.

${ }^{36}$ Así Arenas Esteban (1998/99b), p. 196; otras objeciones en la bibliografía citada arriba en la n. 27 .
} 
ß) la revaluación del "papel de los Campos de Urnas en la gestación del mundo celtibérico, ${ }^{37}$ que hoy en día no sólo aparece apoyado por una, aunque escasa, evidencia antropológica, ${ }^{38}$ sino que también se consigue explicar desde el punto de vista lingüístico, como enseñan los trabajos de de Hoz (1991/92; 1992; 1996/97). En particular, de los dos escenarios visualizados por Arenas \& Martínez (1999), p. 20, al objeto de resolver la vieja aporía ("that the Celtiberian zone and the distribution of the Iberian Urnfields were exclusive [...] did much to undermine the traditional view": Cunliffe [ $\left.{ }^{2} 1999\right]$, p. 139) el segundo -encajando bien además con lo que ahora sabemos sobre la difusión del ibérico (de Hoz arriba en la n. 9)- resulta especialmente atractivo en el marco de nuestros actuales conocimientos: "[...] podemos pensar que fueron los hablantes de lenguas no indoeuropeas los que se instalaron relativamente tarde en determinados puntos de un territorio en el que las lenguas celtas se extendían desde la Europa central hasta las costas atlánticas, donde impusieron su lengua. $\mathrm{Y}$ en pro de esta última posibilidad habla el hecho de que existan indicios de que algunos círculos culturales de Campos de Urnas sí utilizaron una lengua céltica — vid. el caso del grupo de Canegrate [...], lo que deja abierta la posibilidad de que ciertos grupos de Campos de Urnas pudieran haber hablado una lengua céltica que ha sido 'aniquilada' a través del tiempo por la sobreexposición a estímulos mediterráneos o, dicho con más propiedad, no indoeuropeos."

El celtibérico como desarrollo parcial de un celta más arcaico existente en la Península -y específicamente de lo que arriba etiquetamos "celta hispano"- parece ser también el modelo hermenéutico con más verosimilitud lingüística ante las innovaciones detectables en el celtibérico y los arcaísmos detectables en el hispanocelta, discutidos respectivamente en los siguientes apartados III y IV.

\section{ARCAísmo e inNovaciones del Celtibérico}

Sobre el carácter conservador del celtibérico - "ein selbständiges altkeltisches Idiom von archaischem Gepräge" (Meid [2000], p. 2)— la mayoría de los autores está de acuerdo, aunque hay diferencias sobre el grado de arcaísmo que se le asigna. ${ }^{39}$ Así p.ej. creemos que el genitivo en -o\# de los temas en -o- no sea una innovación del lepóntico y del celtibérico, sino más bien una isoglosa más de conservación (desde el *-òd originario de genitivo/ablativo temático del indoeuropeo arcaico, con

\footnotetext{
${ }^{37}$ Formulación de Ruiz Zapatero y Lorrio (1998/99), p. 34 (el espaciado es mío); cf. también de Hoz (1992), p. 19; Burillo (1998), p. 120; Arenas \& Martínez (1999); Villar (2001), p. 120. ${ }^{38}$ Cf. Ruiz Zapatero (1995), p. 101, y de la Rúa (1995), p. 306.

${ }^{39}$ Un modelo posible es el que en su día presentamos en Clermont y Cork (1998a, § II $\beta$, y 1999/e.p., § 2) y que, aunque de forma diferente, llega en cinco etapas a los mismos resultados de Koch (1992): la $1^{\text {a }}$ es la del celta común, la $2^{\mathrm{a}}$ ve el celtibérico ya desarrollado frente al resto del celta o "celta del $2^{\circ}$ período", en la $3^{\mathrm{a}}$ el lepóntico que conocemos se distinguiría del celta del $3^{\circ}$ período (es decir del conjunto constituido por goidélico, galo y britónico), en la $4^{\mathrm{a}}$ el goidélico se percibe como separado del celta del $4^{\circ}$ período o galobritónico, y con la $5^{\mathrm{a}}$ el galo se separaría por fin del conjunto britónico.
} 
sucesivo acortamiento analógico en celtibérico ${ }^{40}$ ), ya que -como subrayamos (2001/e.p.) - encaja perfectamente en el marco de la preservación del sistema declinacional indoeuropeo que se puede apreciar en celta en general y en particular en este dialecto. ${ }^{4}$

Otros rasgos de conservación morfológicos son el mantenimiento del pronombre relativo flexivo, de las desinencias secundarias mediopasivas sin $-r$, del orden sintáctico $\mathrm{SOV}$, mientras que la generalización

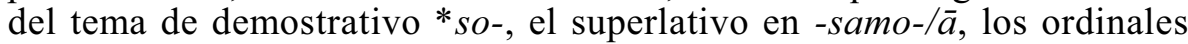
con -eto- $/ \bar{a}$ y la conjunción *yom ya representan innovaciones del celta, aunque no específicas del celtibérico, como —en el campo del léxicoel empleo de *gen-ti-s 'generación' para 'hijo'.

Aún así, se conocen también unas innovaciones específicas como (1) el compuesto bindis $\left(<* g^{w} i \partial m-d i k-s, \quad\right.$ DBSt [1996a]), (2) el pronombre indefinido os-kue-s, (3) el genitivo de plural con -ō- larga generalizada -como ha pasado también en griego, indoiranio o germánico- a los temas consonánticos, (4) la generalización del tema nasal de tipo -un- analógico sobre la desinencia $-u \#(<* \bar{o})$ del nominativo singular, (5) la labialización vocálica ante labial en el morfema de dat.pl. -ubos $\left(<{ }^{*}-o-b^{h} o s\right.$; Eska [1989], p. 141, e idem [1995], p. 12) y posiblemente (6) un infinitivo verbal.

Respecto a la fonética, parece ahora -como se explica en (1999/e.p.), § 10.3, aduciendo el paralelo del grupo itálico- que el desarrollo celtibérico an y am de las sonantes nasales $*_{n}$ y $*_{m}$ haya sido independiente de lo que se observa en el celta del cuarto período y, por lo tanto, constituya una innovación particular del celtibérico (7).

Pero el más llamativo de los rasgos vocálicos de innovación del corpus celtibérico en sentido estricto es (8) la ley de la anticipación palatal formulada en el congreso de Salamanca de 1999; pese a haber sido malentendida, ${ }^{43}$ dicha ley explica los casos en los cuales se produjo palatalización detrás de $a$ u $o$ y antes de una consonante ú n i c a (y además no labiovelar) por efecto de una semivocal palatal (es decir $* y$ ) que precedía la vocal de la sílaba siguiente y se puede formalizar como sigue: $[\mathrm{VCyV}>\mathrm{ViCV}] / a / o-\mathrm{V}\left(\operatorname{con} \mathrm{C} \neq k^{w}\right)$.

Se trata de la palatalización que se puede apreciar en a.i.l.a.m, ${ }^{44}$ *Ailokos,${ }^{45} *$ Againakos,${ }^{46}$ Argailo-/Argailä, ${ }^{47}$ ka.i.n.u,${ }^{48}$ ko.i.tu ${ }^{49}$ con su

\footnotetext{
${ }^{40}$ Cf. DBSt (1992/93), pp. 50s., y (1999/e.p.), § 1.1; más detalladamente ead. (2001/e.p., § 2.1.2.).

${ }^{41}$ Donde p.ej. sigue existiendo la distinción entre sustantivos, con nom.pl. en $-\bar{o} s>-u s$, y pronombres, con nom.pl. en $-o i$, cf. cib. s.to.te.r.o. $i$ (Bot. IV, B.7) desde el tema de demostrativo cib. sto- (opinión divergente en Villar et al. [2001], pp. 113s., que ofrecen una forzada interpretación ad hoc). Las razones por las que hay que mantener el análisis tradicional de la gramática celtibérica se exponen entre otros en DBSt (1998a) §§ I.10. 4ss.; cf. también ead. (1999/01), p. 323 nota 29, y en Arenas et al. (2001), pp. 9s. y nota 36.

${ }^{42}$ En cib. gentis (v. detalladamente MLH V/1, pp. 179ss.), remodelado en el galo (-)gentius, cf. DBSt (1999/01), pp. 319s.

${ }^{43}$ Cf. Villar et al. (2001), pp. 135ss., frente a De Bernardo Stempel (1999/01), pp. 324-328 y en partic. 326 con la nota 51 .

${ }^{44}$ Denominación de un edificio de piedra: $<*$ *aly-a-m, cf. air. ail 'roca' (más detalladamente DBSt [1999/01], p. 326 y nota 53).

${ }^{45}$ Involucrado en el NFam a.i.l.o.ki.s.ku.m, desde un originario *Alyo-ko-s.
} 
Centro y áreas laterales: la formación del celtibérico...

derivado ko.i.ti.n.a, m.e.Tu.a.i.n.u. ${ }^{50}$ y en s.o.i.s.u.m; ${ }^{51}$ en el nombre celtibérico de Togotis ${ }^{52}$ y, no de menor importancia, en el nuevo sufijo -aiko- desde el conglomerado $-a k(o)+y o-,{ }^{53}$ serie sufijal frecuente en el

${ }^{46}$ Desde el mismo *Aganyakos atestiguado en el NL galo Agniácus ( $>$ Aigné), se halla en la
forma de dativo plural a.Ka.i.n.a.Ku.Bo.s, cf. DBSt (1999/01), p. 325 y nota 47 .
${ }^{47}$ Atestiguado también en el derivado a.r.ka.i.l.i.ko.s (nom.plur.) y derivado evidentemente no
por medio de un "sufijo *-ailo-" (así entre otros MLH V/1, p. 40 , al cual, sin embargo, se
remite para el listado de los diferentes hallazgos), inexistente en indoeuropeo y en celta, sino
simplemente por medio de los bien conocidos *-(a)lo- y *-yo-, es decir desde un originario
*argalyos; nótese que la misma serie de sufijos se halla p.ej. en el NInd hispano de tipo galo
Mapalia: NWÄI, p. 455 y s.

${ }^{48}$ NInd relacionado con Caino / Caeno "documentado más de 20 veces entre los Vettones y Lusitanos" (Albertos Firmat [1980/85], pp. 273s., que en [1975], p. 18 n $^{\circ} 209$, registra un NF Caenicorum sobre un objeto de plomo hallado en Córdoba; Palomar Lapesa [1957], p. 55) y formado con el frecuente sufijo ${ }^{*}-y \bar{o}(n)$ de los nomina personalia (NWÄI, pp. 113s.) desde la raíz verbal *kan-, es decir *kanyō(n), el cantor; el paralelo estructural del nombre personal air. Canu/Cano, que también aparece con flexión de tema en - $n$ - (cf. DIL-C- 65 s.v. ${ }^{1}$ cana y NWÄI, pp. 110 y 433, para más referencias y análisis), y la existencia del nombre Canio en el Nórico (OPEL: II, 31) y en una inscripción británica (RIB n ${ }^{\circ} 1483$, dedicada -aunque por parte de un "Germ()" - entre otros "Urse sorori" y "Canioni filio"), contradicen a Villar et al. (2001), p. 137, que hablan en este caso de "etimología meramente hipotética". Se recordarán además apellidos como los Cantore, los Kantor y los Singer, y, a fin de cuentas, también la etimología discutida ahora - y sin embargo rechazada - en MLH V/1, p.147, nos llevaría a una forma pre-celtibérica de la misma estructura (o sea con *anyo $>$ aino).

${ }^{49}$ No aparece en la discusión de Villar et al. (2001), 1.c., aunque sea idéntico al galo Cotiō(n), 'el jorobado > el viejo': así ya DBSt (1999/01), p. 326 y n. 56. El nombre se halla también como Cotu en el Nórico, es decir con el morfema simple $-\bar{o}(n)$ : cf. OPEL, p. 81, Falkner (1948), p. 42 y passim, Lochner v. Hüttenbach (1989), p. 62. Es evidente que una interpretación céltica, además tratándose de una base onomástica tan frecuente y característica en el celta (sobre su origen y desarrollo semántico v. DBSt [1999/00], p. 95), es más indicada que conjeturar con Untermann -en Beltrán et al. (1996), p. 142 y MLH IV, p. 595- la presencia de un nombre griego para explicar los quince (!) hallazgos del cuarto bronce Botorrita.

${ }^{50}$ Leyenda monetal A. 84 reconducible con Arenas et al. (2001), p. 10, y DBSt (ZCP 53), § 9, a la conocida base *medu-an- con sufijación en -yo- : *medwanyōm.

${ }^{51}<{ }^{*}$ sosyōm, genitivo plural masculino del pronombre correspondiente al galo sosio (más detalles y paralelos en DBSt [1999/01], p. 326 y nota 54).

${ }^{52}$ Atestiguado en total cuatro veces en Botorrita I, y en particular dos veces como gen.sg. *togot-yos $>$ to.Ko.i.to.s, o sea de tema en - $\breve{l}$ - con el morfema $*$-yos, que - pese a la información recogida en Villar et al. (2001), p. 135- se halla sin embargo también en el goidélico más antiguo, cf. DBSt (1999/00), pp. 103 y 107, y (2001/e.p.), §1.8. En los otros dos testimonios aparece la forma to.Ko.i.te.i, para la cual quedan abiertas dos interpretaciones: $(\alpha)$ dativo singular con desinencia *-yei analógica sobre la terminación celtibérica de genitivo, aunque no se pueda excluir que se trate de derivación directa desde un tema renovado *Togoit-; $(\beta)$ locativo singular regular *togoty-ei de un derivado adjetival en *-yo-, en cuyo caso la posposición e.n.i ("preposición" en Villar et al. [2001], p. 135) expresaría el sentido de 'al interior', cf. el italiano nel ristorante frente al existente locativo analítico al ristorante. Quedando todavía por demostrar que el corte de la leyenda Iltukoite tenga que hacerse detrás del Il- (así Villar et al. [2001], p. 138) y no detrás de Iltu-, no sería ésta la primera vez que tendríamos en ámbito céltico un topónimo de tipo teofórico.

${ }^{53}$ Como prueban los bien atestiguados air. gablach 'pujante, vigoroso' y gécach 'que tiene muchos descendientes': dos adjetivos en -ăkos que, ampliados simplemente por medio del sufijo $*_{-y o-}$, constituyen las bases —respectivamente $* g^{h} a b^{h} e l-\bar{a} k-y o-s$ > $*_{\text {gabelaikos y }}$ *knk-āk-yo-s > *kankaikos- de los NFF cib. ka.be.l.a.i.ki.s.ku.m y ka.n.ka.i.ki.s.ku.m; cf. para más detalles DBSt (1999/01), p. 327 y notas 62s. Otro ejemplo del mismo tipo derivacional lo proporciona el *kalet-āk-yo-s $>*$ kaletaikos 'fuerte, pujante' involucrado en el 
celta y además atestiguada en celtibérico en la variante $-i k-y o-.{ }^{54} \mathrm{El}$ nombre de Contrebia Belaisca desde un más antiguo *kom-treb-yā Belask-ya con el sentido de "comunidad de los Belaski (o sea de "los afines/pertenecientes a los $\operatorname{Bel}(l) i^{55}$ )", nos hace suponer que -sk- haya sido el único nexo consonántico 'permeable' a la palatalidad. ${ }^{56}$ Asimismo el hecho de que en celtibérico no aparezcan viejos diptongos ascendentes en $-y_{-}{ }^{57}$ y sobre todo que el frecuentísimo sufijo céltico -yako- aparezca preservado tan sólo detrás de $i / e / u \mathrm{C} o$ de nexo consonántico, ${ }^{58}$ hablan en favor de la postulada transposición de la palatalidad.

Por otro lado, el hecho de que la anticipación de la palatalidad no se produzca en unas palabras donde visiblemente había d o s consonantes (como en a.n.ki.o.s, e.s.a.n.ki.o.s ${ }^{59}$ y s.e.Ko.n.ti.a.z), o de las cuales sabemos que tenían consonante doble (como el NInd /abliu/ o /abniu/, ${ }^{60}$ /dannioka/, ${ }^{61}$ y también el *toggias de la inscripción grande de Peñalba ${ }^{62}$ ), nos lleva a explicar de la misma manera las demás palabras

NF ka.l.ta.i.ki.ko.m/s. Por otro lado, el intento de justificar este tipo de derivados "con la abundancia de adjetivos en -aiko- en el Occidente" (Villar et al. 1.c.) no resuelve el asunto, siendo los derivados occidentales en -aiko- palabras de stock indoeuropeo y muchas veces incluso céltico (v. más abajo el apartado VII/11). Menos claro es el análisis de ku.s.ta.i.ko.s -el único derivado de este grupo que es comentado, negativamente, en Villar et al. (2001), p.137- dependiendo del papel sintáctico del "Nutzungsberechtigter" (así Meid, cit. en DBSt [1999/01], p. 326), pensamos ahora que en vez de un original ** gust-āk-yo-s quizá tengamos que reconstruir el genitivo singular * gusta $-k$-yos de uno de los frecuentes nomina agentis célticos con tema en -i- (cf. p.ej. NWÄI, p. 73), es decir de un nom. *gustā-k-i-s.

${ }^{54}$ Sería, por lo tanto, muy llamativo si la variante de esta serie sufijal con ligamento vocálico ("Bindevokal") - $a$ - faltara en celtibérico, como, de hecho, sostienen implícitamente todos los autores reacios a aceptar desarrollos del tipo de -akyo- $>$-aiko-. Al revés, para el supuesto diptongo prehistórico **-aiko- no hay paralelos ni en el indoeuropeo reconstruido ni en las demás lenguas célticas, y tampoco se puede tratar de derivados en -iko- de temas en $-\bar{a}$, cf. DBSt (1999/01), p. 325 con nota 46.

${ }^{55}$ Población de la cual esta Contrebia era la capital. El conocido paralelismo entre los sufijos velares -V-ko- y -asko- (cf. p.ej. a.l.i.ku.m : a.l.a.s.ku.m en Bot.3, Villar et al. [2001], pp. 186s.) se refleja en los genitivos be.l.i.ki.o.m : be.l.a.i.s.ko.m (resp. A. 47 y A. 80). Menos probable sería la interpretación del atributo ${ }^{*} b^{h} e l$-ask-yā como 'luminosa', mientras que Medrano Marqués y Díaz Sanz (2000), pp. 165, operan con datos falsos, lamentablemente repetidos en Villar et al. (2001), pp. 34ss. (el antiguo irlandés bile [recte] 'tree' no tiene etimológicamente nada que ver con el dios que en galés medio se llama Beli, ni éste - por haber tenido en origen necesariamente una sílaba más- con los Beli, cf. resp. NWÄI, p. 211, y MacKillop [1998], 35).

56 También en antiguo irlandés hay nexos consonánticos permeables y otros, como p.ej. cht (cf. GOI, p. 101), que impiden la palatalización.

${ }^{57}$ Según enseña Ballester 1996, cit. en DBSt (1999/01), pp. 324s.

${ }^{58}$ Cf. DBSt (1999/01), p. 327, y el listado de testimonios en Villar et al. (2001), p. 172.

${ }^{59}$ Comentados en DBSt (1999/01), p. 326 nota 51.

${ }^{60}$ Es decir a.ba.l.i.u, o sea más probablemente $A b^{a} l i u$ desde un célt. *abl-yō(n), cuya precedente explicación como célt. *abn-yō(n) en DBSt $(1999 / 01)$, p. 326 nota 51, ha pasado desapercibida para Villar et al. (2001), pp. 136s.

${ }^{61} \mathrm{O}$ sea Ta.n.i.o.Ka de Bot. 3, evidente derivado del celta danno- 'juez', explicación ya ofrecida en DBSt (1999/01), p. 326 nota 51, y no tenida en cuenta por Villar et al. (2001), pp. $136 \mathrm{~s}$.

${ }^{62} \mathrm{O}$ sea TOGIAS frente a CAIAS $<*$ kagyas y en paralelo a OLOCAS por *ollokās, cf. DBSt $(2000$ [2002]), p. 189. 
con yod postconsonántico y sin palatalización de la vocal a/o que precede, como m.a.Ka.s.i.a.m, o sea $/ \mathrm{mak}^{\mathrm{a}} \mathrm{syam} /{ }^{63}$ exceptuando sin embargo unos nombres evidentemente extranjeros como p.ej. Slania ${ }^{64}$ y unos compuestos relativamente tardíos como os+ias. ${ }^{65}$

Eso significa - como ya comentamos (1999/01), p. 326 nota 51, y lamentamos que Villar et al. (2001), pp. 136s., no lo hayan vistosuponer que en los otros hallazgos con falta de palatalización en el contexto $<a / o \mathrm{Cy} \mathrm{V}>$ la escritura también sobrentienda consonantes dobles o largas. De hecho, la escritura epicórica siempre expresa por medio de una sola consonante tanto las consonantes simples como las largas o dobles; sin embargo, sorprendentemente Villar y Jordán Cólera parecen olvidarse de eso, con la consecuencia de que su listado de supuestos "ejemplos contrarios" (op. cit., pp. 136s.) resulta en realidad nulo, porque consiste simplemente en:

(a) palabras que por tener una vocal diferente de $a$ u $o$ antes de * $\mathrm{Cy} \mathrm{V}$ evidentemente no corresponden al contexto establecido para la ley (así $K^{o}$ louniok $^{u 66}$ );

(b) palabras que por tener más de una sola consonante en el medio no corresponden al contexto establecido para la ley (además de los ejemplos ya explicados eso sería el caso de $b^{a}$ razioka ${ }^{67}$, m.e.l.m.a.n.i.o.s ${ }^{68}{ }^{T a b^{a}}$ niu, ${ }^{69}$ mientras que en lugar de "otonia" leeremos con MLH V/1, p. 297, o.to.n.i $i^{70}$ );

(c) nombres con una sola consonante intermedia pero de procedencia ajena (además del ya mencionado Slania los ibéricos Sanion y Tokiosar ${ }^{71}$ );

(d) palabras de composición más reciente que la ley (el ya comentado oz-ias);

(e) palabras que se tendrán que interpretar como las de los tipos b-d o incluso f (OBIOS, r.i.s.a.ti.o.ka; el genitivo de plural irregular TRIDONIECU de Burgos, con prepalatalización en el elemento sufixal -iecu $<*$-iaicum $<*_{-}^{*}$ ak-yōm pero no en la base ${ }^{72}$ );

\footnotetext{
${ }^{63}$ Así recte en DBSt (1991/01), p. 326 nota 51.

${ }^{64}$ Discutido en DBSt (1999/01), p. 325 nota 44.

65 > o.z.i.a.s, cf. la explicación en DBSt (1999/01), p. 326 nota 51, también inadvertida por Villar et al. (2001), pp. 136s.

${ }^{66}$ Correspondiente a la variante CLOVNIOQ (A. 67) y discutido (1999/01), pp. 322s.

${ }^{67}$ ¿Relacionado con el galés bras 'grande' y desde un más antiguo * $g^{w}$ rad-t-ioka?, cf. DBSt y Wodtko en MLH V/1, p. 61.

${ }^{68}$ Por la comparación con otras formas hispano-célticas como los genitivos Melmandi, Mermandi y Melmandicus además de cib. m.e.l.m.a.n.z.o.s < *Melmandyos (así [1999/01], p. 330) y m.e.l.m.a.n.ta.m.a o sea /melmandama/ v. también más adelante al $\mathrm{n}^{\circ} 12 / \mathrm{II}$.

${ }^{69}$ Nótese que el doblete $<$ ta.ba.n.i.u $>$, <ta.m.a.n.i.u $>$ podría recibir una explicación desde la comparación con el desarrollo antiguo irlandés $-b n->-m n-$.

${ }^{70}$ Se trata del nom.sing. de un NInd que en nuestra opinión representa el conocido tema

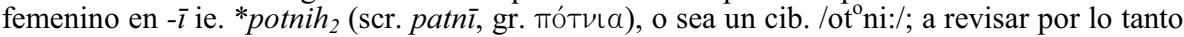
DBSt (1993/96), p. 232.

${ }^{71}$ El primero ya explicado tradicionalmente como NInd extranjero y el segundo leíble también como Tolosar, cf. resp. MLH V/1, pp. 316 y $405 \mathrm{~s}$.

${ }^{72} \mathrm{~V}$. MLH V/1, pp. 413s. No de composición, sino de un acusativo de pronombre iam después de la frecuente abreviatura cib. $\operatorname{kar}(u o)$ se trata en la tésera de La Custodia, discutida
} 


\section{(f) palabras que no pertenecen al corpus celtibérico stricto sensu (ELANDORIAN).}

En relación con el consonantismo, se aprecia la simplificación de los nexos con velar sorda inicial, es decir (9) $* k t>t$ como en cib. r.e.tu.Ke.n.o, ${ }^{73}$ cuyo primer elemento siempre aparece como Rectu- en el resto del celta continental, hispano-celta incluido. El paralelo estructural apreciable en el desarrollo del nexo de velar con sibilante comentado al $\mathrm{n}^{\circ} 10 \mathrm{y}$ el paralelo formal del participio cib. a.ta $<* a$ á $_{\text {-tà }}$ en la tésera de Arecorata (K.0.11) ${ }^{74}$ y del célt. ambactos, que también se manifiesta en Hispania como Ambat-, aunque exclusivamente en el corpus hispano-celta, ${ }^{75}$ nos llevan a suponer que una parte del celta hispano -celtibérico incluido- hubiese cumplido ya, prácticamente, el paso fonético implicado por las grafías galas de tipo Rextu-, duxtir etc. ${ }^{76}$ Y paralelamente también la simplificación de $(\mathbf{1 0}) * k s>s$, como entre otros en cib. e.s(-) 'ex', s.u.e.s '6' y N.e.r.To.bi.s desde un celta común ${ }^{*}$ Nertobrigs,${ }^{77} \mathrm{y}$ de (11) ${ }^{*} p s>s$ como en cib. u.s.a.m.a. ${ }^{78}$

por Jordán Cólera (1998), p. 160. Nótese de hecho que la misma tésera presenta un NF con gen.pl. céltico pero no celtibérico en -un (abajo en el apartado VII/4).

${ }^{73}$ Además del gen.sing. en la estela K. 12.1, para la cual v. la nueva lectura e interpretación por Arenas et al. (2001), el nombre se halla muchas veces, también al nom. r.e.tu.Ke.no.s, cf. el listado de los hallazgos en MLH V/1, p. 302.

${ }^{74}$ Como comentamos en $(2000$ [2002]), p. 187 nota 24, se puede considerar resolutiva a este propósito la solución propuesta por Gorrochategui (1990), p. 298 bajo 2; a corregir por lo tanto -entre otros- Untermann (2001), p. 15.

${ }^{75}$ Cf. IRMN no 53: Ambati CELTI $f$; ; además Lorrio (1997), pp. 48 y 324. El hecho de que Ambatus "tal vez relacionado con la clientela militar" (Álvarez-Sanchís [1999], p. 310) no aparezca en los mismos tipos de fórmulas de los demás nombres individuales se explica seguramente por el sentido original del término, así como se seguía todavía apreciando en el galo ambactus y como aparece en el préstamo gót. andbahts; sobre el desarrollo semántico cf. Campanile (1999), pp. 35s.

${ }^{76}$ Así ya Schmoll en 1959 (cit. en MLH V/1, p. 303). - Sin embargo, afirmar -como hacen algunos autores- que los hallazgos hispano-celtas del nexo -ct- hablen en contra de un desarrollo celtibérico particular, significa volver una vez más a igualar, a priori, a celtas hispanos y celtíberos. Tampoco parece lógico pensar (con Untermann, cit. MLH V/1, 1.c.) que una escritura que utiliza vocales gráficas para indicar a veces las continuas y siempre las oclusivas se aleje de su propio sistema cuando los nexos son de dos oclusivas.

${ }^{77}$ Este desarrollo, conocido también en el lepóntico, no aparece en el nombre del firmante del bronce de Luzaga: pero /Dīvorīks/, escrito <Te.i.u.o.r.e.i.ki.s $>$, por tener al mismo tiempo grafías ultracorrectas como $<\mathrm{ei}>$ por /i:/, no puede ser interpretado como verdadero arcaísmo (a corregir por lo tanto DBSt [1993/96], p. 236), sino representará más bien otra variante del celta hispano, o sea no específicamente celtibérica. Como se sabe desde el "latín" Rufus o desde cualquier lengua viva, y como vimos arriba con respecto a Slania, el hecho de que un nombre esté atestiguado en el corpus propiamente celtibérico no implica que la forma en sí misma o su base onomástica sea necesariamente celtibérica. Así también en el caso de Perkun- + célt. -et-ākā-, para el cual véase ya DBSt (1993/96), pp. 227s. nota 72: "pe.r.ku.n.e.ta.ka.m läßt sich doch am ehesten als vor- bzw. nichtkeltischer übernommener (heiliger?) Ortsname /Perkunetakam/ zu *perkunia (vgl. Hercynia silva usw.) mit keltischer Suffigierung -et-aka interpretieren" (además [1998/a], § I.10.1 nota 91, y [2000], pp. 411s.).

${ }^{78}$ A MLH V/1, pp. 463ss., se añadirá NWÄI, pp. 427s., para la formación de palabra. La silbante sonora -z\# del nominativo plural u.s.a.m.u.z es debida —como en las demás leyendas monetales o en la $1^{\text {a }}$ persona del plural con desinencia secundaria $-m u z<*_{-}$-mos - a la asimilación de sonoridad en sílaba final: -m-s\#>-m-z\#, cf. DBSt (1999/01) p. 329, bajo 2b. 
De los grupos con $n$, el paso * $n s>s$ (que se aprecia, además de $t i-r$ $i-s$, en los acusativos plurales cib. Te.ka.m.e.ti.n.a.s, a.r.z.n.a.s ${ }^{79}$ y m.a.tu.s) es ya del celta común. Que una asimilación - aunque en dirección contraria - haya tenido lugar también entre los componentes del nexo consonántico *nd (12), como ya sugiere la pareja Melmandios/ Melman(n)ios ${ }^{80}$ y es regular p. ej. en britónico, se puede deducir de dos tipos de indicios:

I) la realización de nombres que en las demás lenguas célticas continentales presentan un grupo $-n d$ - por medio de $-n(n)$ celtibérica. Es éste el caso de la agrupación de los Ko.n.i.ku.m

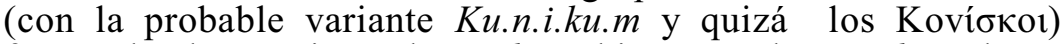
frente al celta continental Condus e hispano-célt. Condisa, de un "radical muy frecuente en la onomástica personal celta"; ${ }^{81}$ de la agrupación de los bi.n.i.s.ku.m en Bot. 3 frente a bi.n.Ti.s con el nexo -nd- todavía preservado por su utilización como término estrictamente legal en Bot. $1 ;{ }^{82}$ y quizá también de unos de los nombres del tipo cib. A.n.a, A.n.u con la agrupación familiar Annicum de Segilus Lubbi f(ilius), magistratus de Botorrita 2, si -como parece por ser tan "frecuente en las regiones célticas"están relacionados con NPP célticos continentales e hispanos como Ando(n) y Andus, Andotus, ANDO[.]0; ${ }^{83}$

II) la ultracorrección -apreciable en gran parte del celta hispano (abajo en el $\S \mathrm{VII} / 17$ ) - de una *-n- etimológica como -nd-. Se trata de un tipo de ultracorrección que se encuentra también en irlandés antiguo y medio y donde a un originario $* n n$ se sustituye a veces un ficticio $n d$, p.ej. en air. cenn $\left(<* k^{\prime}\right.$ wenno- 'cabeza') $\rightarrow$ cend, por efecto de finn < find $(<*$ windo- 'blanco'): ella nos explica por fin el origen de los nombres en -(o)ndo, cuya formación de palabra sólo se halla en el celta de la Península Ibérica (p.ej. en el NFam Bolg-ond-iscum de otro magistrado de Botorrita 2), resultando además problemática desde la

\footnotetext{
${ }^{79}$ Las 'partes' (¿honorarios? ¿parcelas?) < *pr-snä-ns (desde la cara A de Bot. I, como las demás formas citadas), cf. la discusión de su etimología (: air. rann) en NWÄI, p. 550 nota 36; el paso de ${ }^{*} s$ a $z$ en la forma celtibérica es debido al contexto sonoro entre $r$ - y $-n, \mathrm{v}$. $(1999 / 01)$, pp. 328ss. Sobre la asimilación de sonoridad en proximidad de $r / l$ cf. ya Siles (1976/79), pp. 89ss., y ahora Popławski (2000), pp. 13ss.

${ }^{80}$ Para los testimonios en concreto v. arriba en el apartado 8 (b) con la nota 68 . Acerca de la asimilación cf. ya Albertos Firmat (1966), pp. 155 y 305.

${ }^{81}$ Albertos Firmat (1966), p. 93; los hallazgos respectivamente en OPEL, p. 72, Abascal Palazón (1994), p. 334, y MLH V/1, pp. 191 y 210.

${ }^{82}$ Nótese que los seguidores de unas escuelas - como explica la misma Wodtko en MLH $\mathrm{V} / 1$, p. 82- son reacios a aceptar la etimología presentada en 1996 simplemente porque no pueden admitir todo ejemplo de $*_{-} d \mathrm{~V}$ - que no se desarrolle como $*_{-} *_{-z} \mathrm{~V}-$ (v. a este propósito DBSt [1999/01], pp. 328-331).

${ }^{83}$ Cf. Palomar Lapesa (1957), p. 35, quien piensa evidentemente que los nombres latinos de la base Ann- funcionen aquí como Decknamen, y v. más abajo en la n. 99. Para los hallazgos cf. MLH V/1, pp. 25s. y 29; la edición de Fatás 1980 a la 1. 17; OPEL, pp. 108ss. Ejemplos de seguros dobletes de este tipo ofrece Gorrochategui (1993), p. 148. Las formas con asimilación del corpus extraceltibérico se comentan en el § VII/16.
} 
perspectiva del indoeuropeo reconstruido. ${ }^{84}$ Así en el caso del nombre individual cib. l.e.to.n.Tu, gen. l.e.to.n.Tu.n.o.s — a lado de Letondo, gen. Letondonis en el corpus hispano-céltico: su forma originaria fue muy probablemente ${ }^{*}$ Letonno $\bar{o}$, o sea una formación de "nomen_personale" con tema en nasal sobre una más antigua base *Lêton(n)- con geminación expresiva, quizá relacionable con el largo listado de nombres en -onno-/-onnā en Holder: II, 858 y derivada a su vez del adjetivo celta *leito'gris' o eventualmente de la base * $(p)$ let- de 'ancho y llano'.

Característica del celtibérico stricto sensu es además (13) la africación del nexo $d y$ con la sucesiva reducción de la africada [dz] a fricativa sonora $[\mathrm{z}],{ }^{86}$ observable entre otros en s.e.ti.za: galo Sentidius; u.s.e.i.z.u, gen. u.s.e.i.z.u.n.o.s : galo uxedia; u.e.i.z.o.s, dat. u.e.i.z.u.i : galo uedzui ${ }^{87}$ También hay evidencia — como explicamos en $(1998 / \mathrm{b})$ y en (1999/01), p. 330 con detalles y más ejemplos- del mismo desarrollo (14) $[\mathrm{dz}]>[\mathrm{z}]$, originado en este caso de la dental sonora geminada, es decir ðð, p.ej. en cib. ko.n.tu.z.o.s : galo tиみðos.

Finalmente, en el marco de la lenición probablemente celta común de las sonoras destaca (15) el cambio $m>u$ (entre vocal y $n$ ), es decir $\mathrm{Vmn}>\mathrm{Vun}$, que representa una innovación con respecto al estadio fonético intermedio $[\mu]<m$ postulable para todo el celta: así p.ej. en cib. /dizaunei/ desde *didyāmnei, cuyo correspondiente griego $\delta i \zeta \eta \mu \alpha 1$ nos proporciona un sentido perfectamente paralelo al disturbato de la "Lex Ursonensis" (en Botorrita 1 tendríamos por lo tanto "Non licet / nelitom [...] neve / nekue demolitione / masnai disturbare / dizaunei'). ${ }^{88}$ Se trata de una innovación que - como comentamos (1994a), pp. 295 y 285ss. - fue propuesta para el celtibérico ya en 1974 por de Hoz y Michelena y que resulta fonéticamente sencilla y análoga a la que Lambert en varios trabajos desde la mitad de los años ochenta demostró válida para el galo y el britónico (o sea que se establecerá más adelante,

\footnotetext{
${ }^{84}$ Cf. entre otros Albertos Firmat (1966), pp. 287s.

${ }^{85}$ Para los étimos cf. Billy, pp. 92s., Degavre, p. 273, Delamarre, p. 168, y DBSt (1987), pp. 125s. Para los hallazgos v. MLH V/1, p. 221, aunque la tentativa de Wodtko de reconducir el nombre a una base de participio presente en -nt- resulta de la necesidad de la escuela untermanniana de explicar cómo puedan existir palabras con -nd $\mathrm{V}$ - que no evolucionen a **-nz $\mathrm{V}$-; además tropieza con el hecho de que (a) en los ejemplos seguros de -nt- (Segontia, Segontius), la dental no aparece sonorizada; (b) que los "sufijos" -ndo no alternan con **-nto; (c) que los sufijos -ndo no suelen hallarse adjuntos a bases lexemáticas de tipo participial.

${ }^{86}$ Cf. Albertos Firmat (1966), p. 304 y DBSt (1999/01), pp. 328-331, como ya (1998/b); además eadem (ZCP 53), n. 67, y Meid (2000), pp. 22 con la nota 30 y p. 23.

${ }^{87}$ Todos los ejemplos y con más detalles en nuestro trabajo de $(1999 / 01)$, pp. 329s. Cf. además el cib. m.e.l.m.a.n.z.o.s : hisp.-celta *Melmandius visto arriba en la nota 68. Si el bronce "Res" fuera auténtico, se podría quizá añadir al listado de ejemplos también el gen.pl. de NFam /Agezokum/ - o sea a.ka.i.z.o.ku.m - de la base *Agedius atestiguada en el gen. hisp.-celta Agedi (cf. Villar et al. [2001], p. 164), mientras que el nombre de la ciudad de

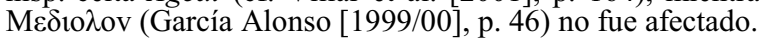

${ }^{88}$ Cf. DBSt (1999/01), p. 330 con la nota 87 y, para la ley, Gorrochategui (1994), p. 21.
} 
en el celta del $4^{\circ}$ período), imponiéndose además por razones de reconstrucción morfológica.

\section{MODERNIDAD Y ARCAÍSMOS EN EL CORPUS HISPANO-CELTA}

A su vez, en el celta hispano de procedencia no específicamente celtibérica se hallan - pese a la atestiguación en general comparativamente reciente de los corpora 5-7 bajo el apartado I.B y a la creación de una "homogeneous superstructure in the Indo-European regions of Hispania, that covered the local peculiarities" (de Hoz [1986/88], p. 201) - al mismo tiempo formas modernas y arcaicas. ${ }^{90}$ Indicamos aquí unos pocos ejemplos:

A) Dicha coexistencia entre formas modernas y arcaicas se puede constatar muy sencillamente observando, entre otros, dobletes como Abrunus $>$ Aburnus, Pistirus $>$ Pissirus $>$ Pisirus, Virot(i)us $>$ Verot(i)us, ${ }^{91}$ o Turobrigénsis > Turibrigénsis, desde el NL Turobriga (con gen.lat. Turobrigae) y para el cual - tanto en la función de origo como en la modernizada de epíteto- se conoce además la asimilación vocálica de tipo labial Turubr-. ${ }^{2}$

No fonética, sino morfológica es la modernidad p.ej. de Touto, evidentemente secundario por su formación de palabra con respecto a Toutonos 'jefe/miembro de la teuta', y análogo a Caturo, gen. Caturonis, hipocorístico con tema en nasal "recortado" del *Katu-rix original, que en Hispania se preserva en la forma fonéticamente modernizada de Caturis; además se formaron desde estos dos las respectivas formas temáticas Caturus/a y Caturonus. ${ }^{93} \mathrm{Un}$ arcaísmo puede que se preserve en el Cadarus occidental, si está relacionado etimológicamente con el Cadarna (cf. cadarn 'fuerte' en británico) hallado cerca de Zaragoza y en Zamora. ${ }^{94}$

B) Unas pocas formas muestran efectivamente rasgos específicos del celta del $4^{\circ}$ período y por eso se atribuyen a los galos que llegaron como tropas auxiliares y comerciantes a la Península Ibérica a partir del s. II a.C. y que alrededor del A.D. 100 están atestiguados viviendo en un pagus Gallorum. ${ }^{95}$ Entre sus características destaca $p<* k^{w}$ 一en Epeicus

\footnotetext{
${ }^{89}$ Cf. la argumentación en DBSt (1994a), pp. 295-296, y más detalladamente (1999), pp. 62 64: de las dos no se toma nota en MLH V/1, pp. 249ss., 367s., 384ss.

${ }^{90}$ Significativa es la observación de Meid en su reciente reseña del estado de la cuestión (2000), p. 25, que el "Hispano-Keltisch im weiteren Sinn vornehmlich durch die Verbreitung keltischer Namen erwiesen wird, die aktuelle sprachliche Situation dabei jedoch weitgehend unklar bleibt".

${ }^{91}$ Cf. Albertos Firmat (1974/76), pp. 71 y 84, y (1966), pp. 252 y 248; Abascal Palazón (1994) s.vv. A éste se remite también para los demás nombres citados en este apartado, siempre y cuando no se especifique lo contrario.

${ }^{92}$ Los listados de hallazgos — aún sin explicación lingüística- en Abascal Palazón (1995).

${ }^{93}$ Para este último grupo cf. Albertos Firmat (1966), pp. 81s., la bibliografía en Rowland (1994/95) y los ns 10 y 14 resp. bajo los apartados III y VII.

${ }^{94}$ Cadarna Vaegium, Rodríguez Almeida en Mayer et al. (1998), p. 172. V. también más abajo al apartado VII/1.

${ }^{95}$ Cf. Marco (1996), pp. 53ss., Burillo (1998), pp. 175-178. Además Marco (1996) identifica a los Volcianos, asentados en Hispania a finales del siglo III a.C. —según documenta Livio-,
} 
y en Mapalia - frente a la conservación de la labiovelar en celtibérico y en general en el celta hispano, como en los nombres de los Equaesi y de los Quarquerni. ${ }^{96} \mathrm{~A} 1$ mismo grupo pertenecería también el tipo Pintamosi derivara - con formación de palabra céltica arcaica - desde "an older Celtic ordinal * $k^{w}$ enk $k^{w}$ tos 'fifth' (> penxtos)", pero Villar, ante su difusión básicamente circunscrita a la zona noroccidental y occidental, lo supone de stock no céltico. ${ }^{97}$ Evidentemente tardíos son los nombres personales del tipo Brittus.

C) Unas veces los diferentes niveles detectables son de tipo lexical, como en el caso del princeps Albionum frente al exclusivamente céltico y de consecuencia más moderno mons Vindius 'mons Albus', los dos en Asturias $^{98}$; o, paralelamente, de ie. seno- 'viejo' en el hispano-celta SENAC-ian- frente a lo que se desarrolla como su sinónimo específicamente céltico en cib. Ko.i.tu (arriba nota 49). La misma explicación podría por lo tanto tener también el NInd M.a.r.ko.s de la agrupación de los Ka.l.i.s.u.m (reconducible a un nom.sg. $\left.{ }^{*} \operatorname{Kal}(l)-i s(s / t)-o-s\right)$ en el listado de Botorrita 3, si procediera de célt. marko- 'caballo' frente al ie. *eḱwo- en los étnicos E.ku.a.l.a.ko.s y Equaesi de los corpora celtibérico e hispano-celta. ${ }^{99}$

D) En ámbito toponímico, corresponde a la capa lingüística más reciente el elemento (-)dunum, con unos pocos y controvertidos

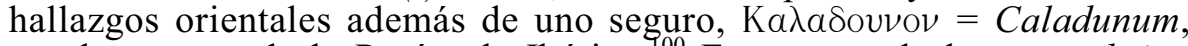
en el noroeste de la Península Ibérica. ${ }^{100}$ En cuanto al elemento -briga (entre otros en Arcobriga $\leftarrow$ célt. arcos 'rezo > Gott', cf. (ZCP 53), y los paralelos Nemetobriga, Tongobriga), estudiado por Albertos Firmat (1990) y generalmente considerado exponente de una celtización más antigua, es preciso subrayar que, aunque se encuentre -como es archisabido- en casi toda la península, la mayoría absoluta de los compuestos atestiguados más antiguamente se halla claramente en el oeste de la Península Ibérica. ${ }^{101}$

E) Se notará, además, la presencia, específicamente en el territorio noroccidental, de topónimos como el Aviliobris estudiado por de Hoz

\footnotetext{
con los Volcae "muy bien atestiguados en el otro lado del Pirineo" (ibid. p. 50, y véase el mapa en Marco [1998], p. 79). Nótese sin embargo que esto no implica necesariamente que su lengua, a la hora de llegar a la península, hubiera participado ya en todas las isoglosas que caracterizan el celta del $4^{\circ}$ periodo.

96 Un listado en Prósper (en prensa) y ahora en Villar (1999), pp. 71ss.; los étnicos bracarenses en Albertos Firmat (1975), pp. 44s.; sobre la divinidad epónima en la inscripción mayor de Peñalba DBSt (ZCP 53), §9 y nota 133.

97 Un resumen de la discusión en DBSt (1995), p. 21, y un mapa ya en Albertos Firmat (1974/76), p. 83.

${ }_{98}$ Albertos Firmat (1975), p. 42.

99 Nótese, sin embargo, que la exégesis tradicional lo identifica con el latín Marcus: Untermann en Beltrán et al. (1996), pp. 148 y 139. Los dos Marcus "Lougi f(ilius)" en las inscripciones latinas citadas (ibid. p. 148) hacen pensar en casos de 'interpretatio Romana' de onomástica personal indígena (en general sobre este asunto Albertos Firmat [1974/76], p. 65).

${ }^{100}$ Rix (1954), p. 102; Luján (1999/00), pp. 59s.

${ }^{101}$ Cf. la repartición en cinco mapas ‘cronológicos' de Arenas Esteban (Veleia 18-19).
} 
(1994) y los del tipo Letiobri, ${ }^{102}$ es decir compuestos con la forma céltica originaria *brig-s del lexema para ciudadela ${ }^{103}$, cuya flexión consonántica se conserva - además del irlandés- también en el nombre de la ceca celtibérica de SEGOBRIS ${ }^{104}$ su frecuencia en Galicia (cf. el mapa en Búa Carballo \& Silva [1994/95], p. 26) resulta aun más llamativa, porque se trata de arcaísmos modernizados fonética $\left(>\right.$-bris ${ }^{105}$ >-bri hasta llegar a los actuales en -bre ${ }^{106}$ ), morfológica (los topónimos por acabar regularmente en -is\# se incorporaron a la declinación latina de los temas en $-i_{-}{ }^{107}$ ) y a veces incluso lexicalmente (Avilio- es un nombre personal latino tardío).

Relacionados con dicha variante toponímica en *-brig-s, y por lo tanto arcaicos también, quizá sean los étnicos que designan los Ärtabros y los Cántabros. La existencia de un nominativo de plural * Kanta-briKes está implícita en el genitivo plural hispano-célt. Cantabrequn (< *Kanta-briK-om y no **Kantabr-ek-om): consecuentemente, las formas del tipo Artabrī y Cantabrī (con el sing. lat. Cantaber $<*$ Kantabris, p. ej. IRMN $\mathrm{n}^{\mathrm{o}}$ 44: Cantabri filius) podrían representar formaciones retrógradas tempranas, "bien en boca de hablantes de una lengua diferente en la misma zona, bien en la transmisión a las lenguas clásicas"; se recordará que por un procedimiento análogo los étnicos galos llegaron a ser temas en $-\bar{a}$ - en la tradición clásica. En sus determinantes Arta- y Canta- es fácil reconocer dos lexemas célticos para piedras y construcciones angulosas: a) galo artuas (ac.pl. con $-w$ todavía preservada detrás de -CC-, v. arriba $\S 1$ nota 11): air. art

${ }^{102}$ Explicados como ablativos de temas en -i-, cf. Albertos Firmat (1975), pp. 34 y 65; Búa Carballo \& Silva (1994/95), p.13.

103 O sea $* b^{h} r g^{h}-s$, desde el cual proceden el femenino irlandés brí 'hill' y quizá unos topónimos italianos, mientras que la forma tematizada *brigā, típica de galo y británico, no representa un latinismo, sino la forma normal para el celta del $4^{\circ}$ período, cf. DBSt (1987), p. 90, y (1996b), p. 116. Nótese que las objeciones presentadas a esta impecable etimología por unos estudiosos de los siglos pasados procedían del entonces escaso conocimiento de la gramática histórica (morfología, fonética) de las lenguas célticas, en general, y del goidélico y celtibérico, en particular, así que hoy en día ya no queda motivo para ir buscando otras explicaciones, además si carecen de apoyo fonético, morfológico y comparativo como la propuesta por Búa Carballo \& Silva (1994/95), pp. 38ss.

${ }^{104} \mathrm{O}$ sea en la leyenda monetal A.89, donde alterna con el étnico plural se.Ko.bi.r.i.Ke.z, es decir /Segobrigez/ (con sonorización de la silbante final detrás de una sílaba atona que empieza con sonora, cf. DBSt [1999/01], p. 329 bajo el apartado ii/b y n. 76, con paralelos); "de Segobrix-Segobris procede la forma actual Segorbe": Búa Carballo \& Silva (1994/95), p. 35. - Cf. además el cib. N.e.r.to.bi.s desde *Nertobriks en la leyenda monetal A.50 y Kaıтóßpı $\xi$ (García Alonso [1993/95], pp.115s.).

${ }_{105}$ Que comparte la isoglosa fonética $k s>s$ del celtibérico clásico, v. arriba bajo el apartado III/9.

106 “[...] la ecuación morfológica entre el top(ónimo) actual [...] Lam-bre y el antiguo $\Lambda$ AMBPI- $\Sigma$ de Ptolomeo 2.6.26, etc. no deja lugar a dudas de que se trate del mismo tipo de top(ónimo)": Búa Carballo \& Silva (1994/95), p.14; sobre el topónimo galaico y su análisis cf. en particular García Alonso (1993/95), pp. 283ss.

${ }^{107}$ El hecho de que dicha transposición - parecida a la descrita por Villar pace Búa Carballo \& Silva (1994/95), p. 33 - no haya mantenido "el elemento gutural radical de la forma original" (ibid., p. 35), que sin embargo en el celta hispánico se hallaba sólo en los casos oblicuos, tiene, seguramente, que atribuirse a la opacidad de estos compuestos toponímicos, que ya no se relacionaban con ningún lexema de uso común. 
'piedra'; b) galo cantalon "viereckiger Freipfeiler" : cib. ti ri-cantam etc.; por lo tanto tendríamos "los (habitantes) de la/s ciudad/es de piedra" frente a "los de la/s ciudad/es cuadrada/s", lo cual no carece de verosimilitud arqueológica. ${ }^{108}$

\section{CENTRO Y ÁREAS LATERALES EN LA TEORÍA LINGÜÍSTICA}

A pesar de unas aplicaciones más antiguas por autores como Vendryes y Meillet, el concepto de "área lateral” en el ámbito lingüístico fue codificado formalmente por Matteo Bartoli en el primer tercio del siglo veinte. ${ }^{109} \mathrm{Su}$ estudio del desarrollo desde el latín a las lenguas románicas le indujo a formular como normas de lo que él llamó "geolinguistica" unas regularidades observables en las relaciones entre los diferentes territorios donde se hablan lenguas que pertenecen a una misma familia: "esse [scil. le norme spaziali] sono [...] un mezzo per trovare il rapporto cronologico fra due o più di due fasi linguistiche" (Bartoli [1945], p. VIII).

Así la "norma delle aree laterali" prevé que la facies lingüística que se halla en dos o más áreas laterales o relativamente periféricas sea más conservadora que la que se documenta en el respectivo territorio central. ${ }^{110} \mathrm{Y}$ de hecho podemos recordar en relación a esto - entre los muchísimos rasgos lingüísticos arcaicos que se pueden hallar en los territorios romances laterales- la conservación de esp. hermoso y rum. frumos frente a fr. beau e it. bello, de esp. mesa y rum. masă frente a fr. table e it. tavola, o de esp. entonces y rum. atunci frente a fr. alors e it. allora.

También un territorio conquistado en época comparativamente más tardía y cualquier territorio más aislado suele preservar la fase lingüística más arcaica, que se presenta en cambio renovada en los centros políticos y en los territorios con mejores comunicaciones. ${ }^{112}$ Desde la mirada de la Roma antigua pueden ilustrar las dos normas respectivamente el esp. comer y miedo frente al it. mangiare y paura y el sardo mannu frente a grande del italiano. ${ }^{113}$ Un ejemplo de la norma del área más reciente en territorios de habla céltica nos lo ofrece la distribución de las variantes del etnónimo *katu-welHna-mnī ('los que

\footnotetext{
${ }^{108}$ Los datos resp. en González Rodríguez (1986), p. 126 nº 81, y Santos \& Hoces (1989), p. 219; Holder s.vv.; DBSt (1987), p. 95; ead. (1998), pp. 609s.; la reinterpretación como 'A ортре́ßai en Strabo (Luján [1999/01], p. 67) procede de paretimología. Las palabras citadas son de de Hoz (1994), p. 354, quien, no obstante, considera "aventurado" proponer etimologías.

${ }^{109}$ Cf. resp. Campanile (1999), p. 14, y Coseriu $\left(1956={ }^{2} 1979\right)$, donde se puede ver muy sencillamente el material citado en este apartado.

110 "Essa dice: Se di due fasi linguistiche una si trova o si è trovata in aree laterali e l'altra in aree intermedie, la fase delle aree laterali è di norma la più antica." (Bartoli [1945], p. 214).

${ }^{111}$ De illā horā, que sustituyó el más antiguo tunc. Para más ejemplos cf. i.a. Bartoli (1945), pp. 36ss.: "Cap. I: Fasi antiche in aree laterali".

112 Resp. "la norma dell'area seriore" y "la norma dell'area meno esposta alle comunicazioni", cf. i.a. Bartoli (1945), p. 72 y 234.

${ }^{113}$ Cf. también las evidencias documentales en Bartoli (1945), pp. 45ss.: “Cap. II: Fasi antiche in area seriore".
} 
Centro y áreas laterales: la formación del celtibérico...

dominan la batalla'): la más moderna, Catalauni - a través de *Kat(uw)aláuni- se halla en el país de procedencia, en este caso la Bélgica, mientras que la forma original, o sea Catuvellauni, aparece en el territorio colonizado de Britania.

Es ahora importante subrayar que, como resulta del material ilustrativo citado, las tres normas de Bartoli evidentemente no implican que las formas lingüísticas no renovadas se queden sin modificar por el simple hecho de que sean arcaísmos: si comparamos en particular el lat. bellus con el fr. beau, el lat. comedere con el esp. comer, el lat. formosus con el esp. hermoso, el lat. mensa con el rum. masă, el lat. metus con el esp. miedo y el lat. tunc con los adverbios resultantes de composición que lo continúan en español y en rumano, podemos apreciar unos cuantos desarrollos recientes que, sin llegar a sustituir los significantes, los han ido modificando poco a poco.

Para el contexto donde aprovecharemos estas observaciones es también relevante el hecho de que unos de los desarrollos que acabamos de observar sólo se hallan en los territorios laterales (p.ej. la $h$ del español frente a la conservación de $f$ en los demás territorios) mientras que otros, como la lenición, son compartidos entre periferia y centro (p.ej. de $d>\varnothing$ en esp. comer y de $b>v$ en it. tavola).

Efectivamente, con respecto a la Romania, hoy en día nadie pondría en duda el hecho de que la misma capa de latín "vulgar" dio origen a dos tipos de territorios lingüísticos, los más innovadores al centro y los más conservadores alrededor, como en el caso de la Cerdeña o de Rumanía. Al mismo tiempo es sabido que los territorios periféricos han desarrollado también unas isoglosas particulares, no compartidas por las lenguas habladas en el centro. ${ }^{195}$

\section{EL MODELO EXPLICATIVO centro vs. áreas laterales APLICADO A LA HISPANIA CÉLTICA}

La aplicación del modelo interpretativo de Bartoli a la Península Ibérica nos llevaría a suponer:

1) que la abigarrada celticidad peninsular hispana proceda originariamente de una facies lingüística céltica en esencia unitaria y más antigua y arcaica que el celtibérico;

2) que desde este celta hispano, que llamaremos "celta hispano común" ${ }^{116}$ se haya desarrollado en el territorio de la Celtiberia, precisamente por ser más central geográfica y políticamente, ${ }^{117}$ la

\footnotetext{
${ }^{114}$ Cf. Hawkes (1971/73), p. 610; sobre el desarrollo lingüístico DBSt (1994), pp. 289s. con bibliografía.

${ }^{115}$ De acuerdo con la "norma dell'area maggiore": Bartoli (1945), p. 217; "Essa dice: Se di due fasi linguistiche una è o è stata molto più diffusa dell'altra, quella è di norma la fase più antica." (ibid.).

${ }^{116}$ Dejando la definición de su relación con el "celta común" en el sentido de "celta de la $1^{\text {a }}$ fase" para otro trabajo actualmente en preparación.

117 "To the north lay the territory of the Urnfield culture, to the west the loosely linked communities of the Atlantic Bronze Age, while to the east and south, along the Mediterranean fringe, the distinctive Iberian culture was soon to emerge as contacts with the east
} 
forma lingüística un poco más moderna que se suele llamar celtibérico;

3) que en los territorios más alejados adonde llegaron los primeros celtohablantes -incluidos también algunos de aquellos celtas de quienes las fuentes antiguas nos dicen que llegaron desde la Celtiberia (v. nota 2) - se preservaron unas formas lingüísticas arcaicas que nos han sido transmitidas en un medio alógeno, es decir lingüísticamente no céltico.

Además puede que en uno o más de los territorios periféricos que acabamos de definir hayan tenido lugar

4) desarrollos lingüísticos particulares, es decir célticos periféricos o incluso no célticos (i.e. del superestrato), mientras que

5) en otros se hayan desarrollado unas de las isoglosas compartidas también por el celtibérico; por último hay

6) territorios en los cuales se manifiestan a la vez isoglosas de tipo celtibérico y otras de tipo extraceltibérico.

Con respecto a la arqueología, las ventajas que resultan de la aplicación del modelo "centro vs. áreas laterales" a la celticidad hispana -modelo sin embargo ya esbozado por Schulten, como resulta de Kalb (1990), p. 340- son evidentes:

a) la llegada de un único núcleo de población celtohablante sería de esta manera suficiente para explicar todas las variedades dialectales que se hallan en la Península, en conformidad con lo que nos dicen hoy en día los arqueólogos, o sea que no hay evidencias claras en favor de migraciones múltiples durante la Edad del Hierro (v. arriba al § II; y al § IV sobre los pocos hablantes del celta del $4^{\circ}$ período documentados históricamente);

b) la presencia de celtas en la Península Ibérica podría de esta manera ser más antigua que los celtas que se documentan en la Celtiberia, resolviendo en consecuencia la aporía por la cual, pese al hecho de que el celta hispano sea uno de los dialectos más arcaicos del grupo céltico si no el más arcaico en absoluto, ${ }^{118}$ la facies celtibérica no se puede atribuir a una fecha muy alta (arriba $\S$ I nota 15$)$;

c) el desarrollo relativamente complejo de la facies arqueológicocultural celtibérica, en la cual concurrieron diferentes vectores

\footnotetext{
Mediterranean states intensified. The Celtiberian zone therefore lay on three periferies and inevitably benefited by absorbing cultural elements from all three.": Cunliffe ( $\left.{ }^{2} 1999\right)$, p. 140.

${ }^{118}$ Como enseña Tovar (1977), la repartición entre Celtas más y menos antiguos encaja con la distinción clásica entre el uso del término Kelt- para los Celtas de Hispania e Italia y de etnónimos procedentes de Gal- para los demás; esta distinción resulta aún más exacta de lo que supuso Tovar si se tiene en cuenta que el tipo Gal-, además de usarse para los Celtas orientales, de Italia y de Francia, se utiliza también para los Celtas de las Islas Británicas (DBSt [1998], pp. 601ss., sin embargo con otra conclusión ya superada). Sobre los originarios

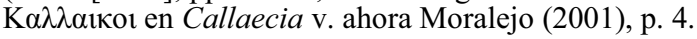


culturales "hasta el momento infravalorados", ${ }^{119}$ coincidiría de esta manera con la reconstrucción de su aspecto lingüístico.

Además - volviendo a la interpretación lingüística del conjunto de los corpora hispánicos- el mismo modelo "centro vs. áreas laterales", al explicar cómo el material lingüístico céltico extraceltibérico puede tener rasgos más arcaicos y más innovadores a la vez (así en el caso del topónimo Aviliobris antes citado), consigue resolver la principal aporía a la cual se enfrentaba hasta ahora el estudio del celta peninsular. En cambio, el hecho de suponer que el celta llegara a la Península Ibérica ya en su estadio celtibérico o que el celtibérico fuera de cualquier forma el celta más arcaico que llegara a la Península Ibérica, pese a ser la postura actual de la mayoría de los estudiosos (arriba § II bajo A), dificulta innecesariamente la explicación de todo el material lingüístico que no comparte las innovaciones del celtibérico stricto sensu.

\section{LA VARIEDAD LINGÜÍSTICA DE LOS TERRITORIOS FUERA DE LA CELTIBERIA}

Pese al hecho de que en este capítulo podemos ofrecer sólo unos pocos ejemplos de la variedad de formas hallada en el celta peninsular hispano - reservando una indagación sistemática para un trabajo futuro-, resulta que con la ayuda de la teoría de las áreas laterales, es decir si asumimos que una primera capa lingüísticamente céltica se extendió hasta los bordes de la península para retraerse después y renovarse en territorios más céntricos, podemos explicar de forma muy sencilla unos cuantos fenómenos de variación lingüística.

Debido a la naturaleza de los corpora lingüísticos no celtibéricos de Hispania, disponemos de bastante isoglosas fonéticas, pero solo de unos pocos rasgos morfológicos para clasificar el celta hispano con respecto a su relación con el dialecto o lengua celtibérico, aunque, afortunadamente, los rasgos morfológicos que se hallan no son por eso menos eficaces a la hora de hacer resaltar las diferentes áreas dialectales.

En concreto, el modelo "centro vs. áreas laterales" nos explica sencillamente:

1) que en un mismo territorio fuera de la Celtiberia aparezcan nombres con formación de palabra a la vez más arcaica y más moderna que la que se halla en Celtiberia misma. P.ej. los teónimos célticos de Lusitania Bor-us y Borm-anicus (resp. desde * $b^{h}$ or-ó-s y * $b^{h}$ orm-an-iko-s) frente al tipo con sufijo *-mo- (Bormo, atestiguado en la Keltiké) contenido en el nombre de agrupación familiar cib.arc. bo.r.m.e.s.ko.m y en el NL que constituye la basis del cib. /Borvodurika/; ${ }^{120}$ otro ejemplo es el NInd. Cadius (: air. cáid

\footnotetext{
${ }^{119}$ Cf. Arenas (1998/99a), p.7ss., y (1998/99b).

120 Resp. genitivo de plural en la leyenda monetal A.81, cf. DBSt (ZCP 53), § 2 con bibliografía, y la nueva lectura de la tésera de Uxama por García Merino \& Untermann (2002). Es evidente que el nexo -rv- en Bo.r.u.o.Tu.r- representa simplemente la expresión gráfica de la regular lenición céltica de la nasal labial detrás de otra sonante: $* / \mathrm{Rm} />/ \mathrm{R} \mu /$,
} 
'honrado, noble') con respecto al Cadarus que, además de en Cadaric(), aparece - junto con la isoglosa $\mathrm{n}^{\circ} \mathbf{1 2}$ (es decir con $/ z /$ de la geminada *dđ atestiguada en Caddecun <*kaddikōm) - en el Casarico(n) de Soria y en el cib. ka.za.r.o.ku.m, mientras que Cadarna parece representar un estrato aun más reciente; ${ }^{121}$

2) la preservación de lexemas morfológicamente arcaicos - aunque eventualmente innovados en unos rasgos- en territorios periféricos, como en el caso de los topónimos en -bris (-bri > -bre) y de los étnicos de los Artabri y de los Cantabri (resp. los que viven en ciudades con costrucciones de piedra/cuadradas), según vimos en el apartado IV(e). A este grupo pertenecen - como resulta de la discusión y cronología relativa en NWÄI, pp. 423 nota 3 y 427 430 - también los restos de superlativos arcaicos en ie. *-isto- que se hallan en el corpus hispano-céltico: cf. el étnico Caristi, el teónimo Baelistus en Álava y el NL Segestica frente a los tipos ya célticos en -(is)amo- atestiguados -además del corpus hispanocéltico- en celtibérico, como entre otros Segisama : s.e.Ki.s.a.m.o.s y los ejj. al $\mathrm{n}^{\mathrm{O}} \mathbf{9}$ y $\mathbf{1 5}$

3) el carácter no composicional de la mayoría de los nombres individuales atestiguados en el corpus celtibérico - considerado asombroso por la mayoría de los estudiosos- frente al tipo composicional característico del indoeuropeo y del celta tradicional que se conserva en los demás corpora del celta hispano ${ }^{123}$ (entre otros el extranjero <Deivoreik $\mathrm{s}>$, Ogrigenus ex cohorte Aestureru(m) [sic] et Callaecoru(m), Admata y Andamius en

cf. entre otros Salmantica $>$ Salvantica y el galo *anmana $>$ anvana (diversamente Untermann op.cit. p. 137s.).

${ }^{121}$ V. el mapa de Albertos Firmat (1974-76), p. 77; eadem (1975), p. 10 no 11 (Cadarig()); González Rodríguez (1986), pp. $\mathrm{n}^{\text {os }} 65,66,88$; LEIA-C-9s. y NWÄI, pp. 69, 415, 439 y 527, además 529ss. sobre la relación entre derivaciones con morfema - $i$ - y -ro- (cf. también el galo -cadros); MLH V/1, p. 146; arriba § IV bajo A.

${ }^{122}$ Cf. respectivamente García Alonso (1999/00), p. 41; la ficha P.E.T.R.A.E. elaborada por la colega Pilar Ciprés - a quien agradezco vivamente su informe del 11 de diciembre de 2001 - para el corpus de las inscripciones romanas del País Vasco de próxima publicación; DBSt (ZCP 53): *Bel-isto-s vs. galo Bel-isama; la nota 14 al $§ \mathrm{I}$; los ejemplos en MLH V/1, pp. 325ss., y Jordán Cólera (1998), p. 86, a integrarse con la reconstrucción en NWÄI ll.cc.

${ }^{123}$ Cf. Schmidt (1992), p. 47 (el espaciado es mío), quien nos habla de "a) the lack of compounds which reminds us of the L a t i n epigraphy of Gaul where among the Gaulish PNN the one-stem formations outweigh the compounds by far $[\ldots]$; b) the occurrence of hypocoristic names characterized by consonant-doubling", "a widespread CC feature": "Así pues, es clara la preferencia entre los celtíberos por nombres simples formados por derivación o por mera tematización a partir de una única raíz." (Luján Martínez [1996], p. 215, aunque sin referencia a los trabajos de Schmidt y con una interpretación cronológica contraria a lo que sabemos del indoeuropeo reconstruido). Para la evidencia (con respecto al territorio celtibérico unos autores añaden también Aliogenus, sin la isoglosa celtibérica del $\S$ III/8 [v. también el $\mathrm{n}^{\circ} \mathbf{1 1}$ más adelante], *Belligenes de la transmisión secondaria, evidente traducción del celta *Katugenos [KGPN, pp. 146s.], y Sangenus, atestiguado sin embargo ahora también en Cáceres), v. arriba la nota 77 al § III/10; Albertos Firmat (1976/79) s.vv.; eadem (1980/85), pp. 288s.; Palomar Lapesa (1957), pp. 23s., 35 y 115; los $\S \S$ IV/A y III/9; MLH III/2, p. 370; Hernández Vera \& Núñez Marcen (1989); Correa (1989) y MLH IV, p. 168, con más bibliografía. Para los demás nombres citados en todo este apartado, siempre y cuando no se especifique diferentemente, se remite a Abascal Palazón (1994) s.vv. 
Centro y áreas laterales: la formación del celtibérico...

Lusitania, Anderca, Caturis y Rectugenus, además del elevado porcentaje de nombres de stock céltico compuestos hallado en inscripciones ibéricas, p.ej. Boduoris abajo al $\mathrm{n}^{\mathrm{o}} \mathbf{1 4}$, sin olvidar Lu(g)eikar() en Graccurris y también compuestos "tartésicos" como Aiburis). Evidentemente nombres derivados sin composición como l.u.bo.s : Lubbus (o U.s.e.i.z.u vs. lep. UFamo-Kozis) se habían puesto de moda en las áreas más céntricas, donde sólo quedan escasísimos restos del tipo tradicional (específicamente r.e.tu.Ke.n.o.s y m.e.z.u.Ke.n.o.s en el corpus epicórico) y también se hallan nombres de stock no indoeuropeo.

Asimismo el hecho de que un grupo de los antiguos NPP célticos compuestos con *-geno-s sea afectado, como entre otros Catuenus, Matuenus, Matu[e]niq(um), ${ }^{124}$ por la isoglosa $n^{\circ} 21$ (caída de -gintervocálica), y otros como Matucenus por la isoglosa $\mathrm{n}^{\circ} \mathbf{2 2}$ (ultracorrección $\mathrm{M}>\mathrm{T}$ ) nos confirma que estamos en presencia de territorios lingüísticamente laterales;

4) los varios tipos de genitivo de plural masculino no reconducibles al -um desarrollado en celtibérico clásico del más antiguo -ōm que aparece todavía atestiguado en el celtibérico arcaico de las leyendas monetales (cf. a.bu.l.o.ku.m, ba.l.a.i.s.o.ku.m vs, s.e.Ka.i.z.a.ko.m, ko.n.te.ba.ko.m. ka.r.bi.ko.m o e.ku.a.l.a.ko.m). ${ }^{125}$ Estos genitivos "extraceltibéricos" estudiados sistemáticamente por González Rodríguez (1986) se suelen dividir en tres tipos: los en -om (i), los en -on (ii) y los en -un (iii). No obstante, los ejemplos de -om (i) en el corpus hispano-celta son más que escasos (cf. ahora Letondiquom en Ávila) ${ }^{126}$ y, por proceder de territorios al oeste de la Celtiberia, representarán probablemente restos del tipo en $\overline{-} \bar{m}$ del celtibérico arcaico, es decir, formas residuales de un área que se sustrajo al paso -ōm > -um del celtibérico clásico. En la mayoría de los casos, estos genitivos plurales con $-O-$, por estar acortados, no se pueden distinguir (como p.ej. los "Turoco(m)" frente a los "Eburanco(n)") del tipo, mucho más frecuente, en -on (ii), o sea con modernización de la nasal final ${ }^{*}-m$ en $-n \#$. Claros ejemplos de este segundo tipo

\footnotetext{
${ }^{124}$ Nótese que -VgV- se mantuvo — además de en Magilanicum también de área vetona- en la indicación de paternidad (Magilonis) de la dedicataria Tritia de esta misma inscripción procedente de Yecla de Yeltes: por lo tanto, la caída de la - $g$ - intervocálica tiene que ser más antigua y proceder de otra área dialectal; cf. —además de Sánchez Moreno (1996), p. 129Palomar Lapesa (1957), pp. 61 y 141; Albertos Firmat (1974/76), pp. 66 y 83 con mapa; eadem (1975), pp. 18 y 31; Evans (1976/79), p. 124; Coelho Ferreira (1986), p. 270.

${ }^{125}$ Resp. en K.0.1, K. 16.1 y A.78, 75 y 63 (con CNH 287). De la última leyenda se conoce también la variante e.ku.a.l.a. $k^{u}$, acortada conformemente a los módulos de genitivo de plural latinos (es decir como los CLOUNIOQ / $k^{o}$ louniok $^{u}$ de A.67), según se explica en DBSt (1999/01), p. 322s. (falta en Villar et al. [2001], p. 89). En celtibérico tardío aparece además una forma -oum, que se explica como analógica sobre la desinencia de genitivo plural femenino -aum: se trata de VORAMOS EDNOUM 'summus avium' en K.3.7, cf. DBSt (1991), p.41, y (ZCP 53), § 3 .

${ }^{126}$ Gómez-Pantoja (1994/96), p. 83 con bibliografía, aunque la referencia a González se atribuirá recte al $\mathrm{n}^{\circ} 25(\mathrm{c})$ p. 84 . Los ejemplos más abajo corresponden a los $\mathrm{n}^{\mathrm{os}} 115 \mathrm{~s}$. de González Rodríguez (1986) y a unos additamenta —de Cifuentes, en HEp 2/1990, pp. 125$126, \mathrm{n}^{\circ} 415$ (n.v.) - que agradezco a la misma autora.
} 
son el Ateroecon portugués, Sailciecicon de Salamanca y Belvicon de Burgos, ${ }^{127} \mathrm{y}$, en cuanto a su vocalismo, no sabemos si la desinencia -on $(\alpha)$ procede del morfema $*_{-}$ŏm (o sea de los temas consonánticos, forma que se generalizó p.ej. en el celta del $3^{\circ}$ período) o $(\beta)$ representa el mismo $*_{-} \bar{o} m$ que se continúa en celtibérico, pero sustrayéndose al paso $-\bar{o} m>-u m$ del período clásico y quizá incluso desarrollándose como /-ŏN/. En ambos casos el desarrollo que tuvo lugar fue, por lo menos en parte, independiente de lo que pasó en el área central, y eso se puede decir también con respecto al tipo en -un (iii), que se halla en territorios más alejados, sobre todo entre los Cántabros, como indica el mismo Cantabrequn (arriba en el $\S \mathrm{IV} / \mathrm{E}$; cf. además Caddecun en el $\S$ VII/1, Boddegun y Celtigun con la isoglosa $\mathrm{n}^{\mathbf{0}} \mathbf{2 0}$, así como un Balatuscun entre los Arévacos). ${ }^{128}$ Que este tipo no continúa directamente el -um del celtibérico clásico con la nasal simplemente remodelada, sino más bien un ${ }^{*} \breve{o} N$ (sea eso original o intermedio) se deduce, además, del hecho de que aparece ya en el corpus epicórico: ${ }^{129} \mathrm{cf}$. la leyenda monetal A. 60 o.l.ka.i.r.u.n $<*$ olkaryōm 'de los ciudadanos de Olca' (nom.sg. *olka-r(o)-yo-); y el genitivo v.e.n.ia.ku.n <*venia-kōm 'de los familiares' en la tésera K.18.3;

5) la forma - modernizada respecto al celtibérico- de dativo plural en -bo, es decir con desinencia asigmática como la del galo-griego, que aparece ya varias veces en las inscripciones tartésicas (MLH IV, pp.166s., y arriba nota 10) y en la tésera celtibérica de Uxama (tu.r.e.i.bo). Además el morfema -bo "ist im (nichtkeltiberischen) Westen die geläufige Form des Dativ-Ablativ Plural und erscheint inschriftlich in zahlreichen pluralischen Götternamen", donde, al lado del tipo Arabo, Arquienobo, Lucubo, se halla también su modernización en Lucoubu; ${ }^{130}$

6) los nominativos singulares de temas en nasal en inscripciones ibéricas con la misma retención de la $-\bar{o} \#$ larga final que se aprecia en el $\mathrm{n}^{\circ}$ 4: entre otros kanio y touto, mientras que para los nombres atestiguados, como Caturo ( $\S \mathrm{IV} / \mathrm{A})$, en inscripciones latinas es muy difícil excluir que se trate de una adaptación al medio latino, como en el caso del Ablo con gen. Ablonis en el segundo bronce de Botorrita frente a los auténticos $A b^{u} l u$ con gen. $A b^{u} l o s$ del primero; ${ }^{131}$

\footnotetext{
127 Reconducibles el primero a *(p)ater-ok-yōm y el último a *bellovikōm; cf. González Rodríguez (1994), p. 171, eadem (1986), n ${ }^{\text {os }} 172$ y 53, y Sánchez Moreno (1996), p. 131.

${ }^{128}$ González-Rodríguez (1986), n ${ }^{\text {os }} 55$ s., 91 y 49; Gómez-Pantoja (1994/96), pp. 80 y 82.

${ }^{129}$ V. Octavi-olca (Gorrochategui [1999/00], p. 150), el nombre de los Olcades, los Bracari para la formación de la palabra, con el $\S$ III/8 arriba y el $\mathrm{n}^{\mathrm{o}} \mathbf{1 1}$ aquí abajo sobre la prepalatalización. Con respecto a la tésera de la Custodia de la cual procede el segundo hallazgo, el suponer, entre otros con Rubio (1999), p. 141, que el mismo signo ${ }^{\top}$ representara dos fonemas diferentes, o sea $/ \mathrm{n} / \mathrm{y} / \mathrm{m} /$, en la misma inscripción (!), y además cuando en el mismo texto hay una tercera nasal, que es una $/ \mathrm{m} /$ expresada - como esperable - por el signo $\uparrow$, es evidentemente una petitio principii.

${ }^{130}$ Meid (2000), pp. 13 y 22 con la nota 34. El probable /Duribo/ resulta ahora de la "Revisión" de García Merino \& Untermann (2002), en part. p. 136.

${ }^{131}$ Correa (1993), p. 103 (y 113, 110), y v. arriba § I.B al punto 3; de Hoz (1999), pp. 145s.; DBSt (1998/a), § I.3.2.2.
} 
7) restos de temas en nasal con preservación del morfema oblicuo -on- (p.ej. en Arconicum y Caburoniq(), hallados en territorio vetón) frente a la generalización de la $-u \#$ del nominativo céltico en celtibérico;

8) restos de los diptongos antiguos como el eu de la Compleutica gallega frente al cib. ko.n.bo.u.to de A.74 y de Teuto frente a to.u.ti.n.i.ku.m, aunque el NInd sea relativamente moderno por lo que respecta su formación de palabra (§ IV/A); quizá también unos ou, p.ej. de los Cloutius y Toutoniqum vetones, frente a la monoptongación de otros territorios del celta peninsular como se vislumbra del hapax celtibérico to.ti.n.i.ku.m en Bot. 3. Paralelamente ei podría representar el diptongo verdadero en la periferia, mientras que grafías ultracorregidas como p.ej. cib. e.s.u.e.i.ku (<*eks-wik-ō), a.r.e.i.te.n.a y quizá <Letondo> (§ III bajo 11/II) presuponen su monoptongación por lo menos en el territorio más céntrico, monoptongación que aparece entre otros también en la dedicación vetona Netoni deo. Además en el corpus hispano-céltico se preserva -como en otras áreas periféricas del celta continental- la base Tauro- (en variados hallazgos y derivados), mientras que en el corpus celtibérico ha aparecido también la forma específicamente céltica TARVODURESCA, es decir con metátesis; ${ }^{133}$

9) la conservación en un texto comparativamente reciente de la antigua variante Bletisam(a), la cual por su regular desarrollo céltico $* \mathrm{Vpl} \mathrm{V}>\mathrm{VblV}$ fue evidentemente originada en sandhi postvocálico - en este caso probablemente detrás de una preposición que acababa en vocal - a partir del mismo topónimo céltico * pletisama (Ledesma) que en su atestiguación celtibérica sólo aparece en la forma (absoluta) l.e.ta.i.s.a.m.a $;^{134}$

10) fenómenos de epéntesis que se manifiestan en el centro, como en el caso de cib. tu.r.u.m.o.Ku.m, mientras que las áreas laterales

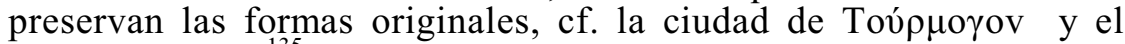
étnico Turmogi $;^{135}$

\footnotetext{
${ }^{132}$ Cf. Abascal (1999), p. 296, Albertos Firmat (1975), p. 13, y v. al § III/4.

${ }^{133}$ Cf. Luján (1999/00), p. 60, y García Alonso (1999/00), p. 33; Albertos Firmat (1966), pp. 225 y 300 § 17; eadem (1974/76), p. 85; Palomar Lapesa (1957), pp. 105s.; Salinas de Frías ( $\left.{ }^{2} 1986\right)$, pp. 55, 85 y 90, y Sánchez Moreno (1996), p. 131; DBSt (1999/01), p. 324; ead. (1999/00), p. 90); MLH V/1, resp. pp. 369 y 363s. Véase además э Tarbu en Albertos Firmat (1975), p. $33 \mathrm{n}^{\circ} 18$. Los casos de $a u$ en el noroeste - cf. el mapa de los "Derivatives of *teutā (after Albertos)" en de Hoz (1986/88), p. 200- como p.ej. el NP Tautalos (Salinas de Frías $\left.{ }^{2} 1986\right]$, p. 35) se pueden explicar por asimilación a una $a$ en la sílaba siguiente (v. abajo al $n^{\circ}$ 19), es decir también desde un estadio intermedio con *ou.

${ }^{134}$ Cf. DBSt (1987), p. 125, (1993/96), p. 234, y (1994b), p. 236 nota 87 con bibliografía. Un paralelo sería el topónimo galés Borth (en Ceredigion), donde también se ha generalizado la variante con lenición inicial (desde Porth $\leftarrow$ lat. portus), original de contextos postvocálicos, como detrás de la preposición y 'to'. A corregir, por lo tanto, la atribución a un sustrato precéltico por Álvarez-Sanchís (1999), p. 318s.

${ }^{135}$ Discutidos - junto con casos de epéntesis reales y gráficas en el hispano-celta - por DBSt

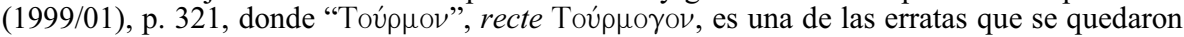
por no haber recibido pruebas.
} 
11) los territorios que esquivan la regla de la anticipación palatal: ${ }^{136}$ la Salionca de los Autrigones y NInd como Coria y Coriana, Vrocius, además de dos dedicaciones (deo) Togoti del área vetona frente al cib. /Togoitei/; también hay unas áreas adonde se ha extendido el nuevo sufijo -aico-, -eco-, pero sin que participaran regularmente en la isoglosa de la palatalización (cf. el epíteto Cariocieco, mientras que en Arbariaico la discrepancia es atribuible a la cronología relativa: *(p)rHi-b $b^{h} e r-y \bar{a} k-y o-s>*^{*}$ areberyáicos $)$. De cualquier forma, la anticipación palatal es una isoglosa que puede aparecer también fuera de la Celtiberia, cf. la dedicación Senaico realizada por un cántabro (desde un nom. *sen-ākyo-s "'alt' > 'ehrwürdig'"), el personal Caldaecus en León (desde el *kal(e)t-āk$y o-s$ que constituye la base del nombre de agrupación familiar cib. ka.l.ta.i.ki.ko.s), la agrupación de los Coironiq(um) en Ávila (derivado de la conocida base *koryon- 'jefe del ejército') a lado del

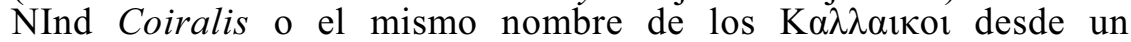
precedente *kall-ak-yo- (sucesivamente objeto de resufijación en Callaec-ia y con sonorización inicial secundaria, $\mathrm{n}^{\mathbf{0}} \mathbf{2 3}$ ).

Unas de las áreas de este segundo tipo son evidentemente laterales por documentarnos contemporáneamente otras isoglosas que excluyen el área central de la Celtiberia, como la sonorización del $\mathrm{n}^{\circ} \mathbf{2 0}(\mathrm{T}>\mathrm{M})$, p.ej. en el mismo morfema -aigo-. Aún en otros territorios se halla, como acabamos de ver, en vez de -aico- la variante -aicio-, probablemente con resufijación en -yo- del mismo conglomerado sufijal *-äkyo- (cf. en Extremadura el teónimo

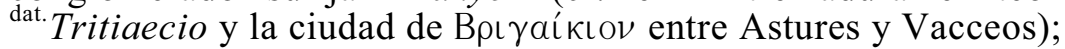

12) la diferente respuesta de los territorios extraceltibéricos a la africación de $d y:{ }^{137}$ así frente al tipo celtibérico con fricativa silbante derivada de la simplificación de la africada (s.e.ka.i.z.a, o sea /Segezal < *Segedza $<{ }^{*}$ Segedia $)$ encontramos también la semplificación opuesta, es decir formas en las que de los dos

\footnotetext{
${ }^{136}$ V. para todo esto la discusión en el § III bajo el apartado 7. Que estamos efectivamente en presencia de una anticipación de palatalidad resulta además de la variedad de los nuevos "sufijos", dado que diferentemente tendríamos que reconstruir no sólo un antiguo **-aiko-, sino también un **-aino- (para Kav́kalvos, Palomar Lapesa [1957], p. 62, más probablemente originado de *Kauk-an-yo-s, v. también arriba en la nota 50), un **-aito- (para Kó $\mu \beta \alpha \imath \tau o v$ en Callaecia, Luján [1999/00], p. 65, más bien desde *Kamb-at-yo-m), un **-ailo- (para la Apraí $\alpha$ de los Arévacos, García Alonso [1999/00], pp. 39s., más bien desde *Arg-al-yā) etc. Las formas citadas resp. en Solana Sainz (1991), p. 171; Palomar Lapesa (1957), p. 113; Álvarez-Sanchís (1999), p. 311; Coelho Ferreira (1986), p. 290; García Martínez (1997/99), p. 179, Untermann (1985), pp. 350 y 360, DBSt (ZCP 53); MLH V/1, p. 154, y DBSt (1999/01), p. 325; Albertos Firmat (1966), pp. 92 y 95 y el mapa de eadem (1974/76), p. 80; Salinas de Frías (21986), pp. 54 y 84; Moralejo (2001), p. 4; DBSt (ZCP 53) con bibliografía; García Alonso $(1993 / 95)$, p. 302s. Es interesante constatar que uno de los étnicos de la Irlanda primitiva es el de los Kopıovoot, más arcaico del Coironiq comentado en el texto, aunque con la ultracorrección "hispánica" $-n(n)->-n d-$ del no 17.

${ }^{137}$ V. arriba al § III bajo el apartado 13; MLH V/1, pp. 322 y 148s. con bibliografía; ibid. p. 207; DBSt (1999/01), p. 331; eadem (2001), p. 167; Prósper (1997), p. 277; la relectura de una inscripción hallada en Olmillos (Soria) por H. Gimeno y M. Ramírez (Veleia 18-19). Otros ejemplos con alternancias entre $-z$ - y el $-d$ - extraceltibérico ofrecen Villar \& Arboledas (1999), pp. 432ss.
} 
componentes de la africada no se conserva la silbante sino la dental $\left(\Sigma \epsilon \gamma \eta \dot{\delta} \eta, \Sigma \in ́ \gamma \eta \delta a\right.$, o sea Segeda $<{ }^{*}$ Segedza $<*$ Segedia $)$. Este

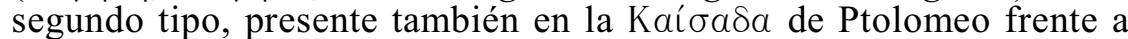
Ka.i.s.e.z.a de las monedas (A.83), tiene por lo tanto que ser el resultado de un cambio paralelo pero completamente independiente del territorio celtibérico. Otros territorios -en el oeste y en el noroeste- no participan ni en la africación del nexo, cf. - además del Cadius comentado en el $\mathrm{n}^{\mathrm{o}} \mathbf{1}-$ cerca de León el gen. de NInd Quesadioci (¿de la raíz * $k^{w}$ eis- 'notar'?) y el dat. de epíteto teonímico Segidiaeco, el cual, pese a su arcaicidad con respecto a la isoglosa en cuestión, comparte no obstante con el celtibérico el nuevo sufijo -aiko-, además en la versión modernizada (isoglosas $\mathrm{n}^{\circ}$ 11 y 24). En el NInd Diocus la falta de africación podría ser debida a la composición, por tratarse etimológicamente del mismo compuesto negativo *dē+oḱus que aparece en el galés diog 'lazy; slow';

13) con respecto al grupo $* k t,{ }^{138}$ la variación entre los desarrollos (i) sin asimilación (Rectugenus), (ii) con asimilación a $t$ como en celtibérico (p.ej. en el Ambatus frecuente entre Vettones y Lusitanos), y (iii) con resultado -st-, que no puede proceder del tipo (ii) o celtibérico: cf. el nombre de los Contestani, evidente derivado de la misma base del galo Contextos 'compañero' y del air. cuitechtae 'compañía';

14) con respecto al grupo $* k s$, casos aislados de preservación del grupo como $<$ Deivoreik ${ }^{\mathrm{i}} \mathrm{s}>$ frente a la asimilación, que en este caso se halla también fuera de la Celtiberia, p.ej. en el bo.tu.o.ri.ś de Pech Maho; ${ }^{139}$

15) con respecto al grupo ${ }^{*} p s,{ }^{140}$ casos de simplificación a $-k s$ - como en Uxama, Uxentius, frente a los más modernos con -ss- (Usseitiom, Ussueitio/cum; Crissus frente al galo Crixsus 'crespo') hasta llegar al Useitius de Bot. 2, con -s- como en el cib. Useizu 'Maximus'. Aún otro tipo de simplificación podría hallarse en el epíteto teonímico Araugelensis si procediera, a través de *are-ukel-, de un original *peri-ups-el-;

16) con respecto al grupo $n d,{ }^{141}$ la alternancia entre su preservación, como en el teónimo occidental Endovellicos ('El (dios) que ve el interior'), y su asimilación a $n n$ también fuera de la Celtiberia, como en los Laribus Anaecis o sea *Andaicis (a confrontar con las matres

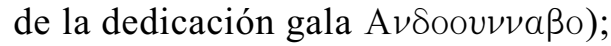

\footnotetext{
${ }^{138}$ V. arriba al $\S$ III bajo el apartado 9 y cf. entre otros Salinas de Frías $\left({ }^{2} 1986\right)$, pp. 66s.; Álvarez-Sanchís (1999), pp. 308ss.; ad RIG-L-10 Lambert (1990), p. 383, y LEIA-C-282.

${ }^{139}$ Que por eso, como también los primeros dos compuestos en la nota 4 al $\S$ I.B(3), no será "gallisch" (MLH III/2, p. 370); cf. entre otros también el "tartesio" Aiburis aquí en el apartado 3 y v. arriba al § III bajo el apartado 10.

${ }^{140}$ Cf. Gómez-Pantoja (1994/96), p. 85; MLH V/1, p. 466, al cual se tendrá que añadir DBSt (1999/01), p. 329, como ya (1998/b), §4; Delamarre, p. 108; arriba § III/11.

${ }^{141}$ V. el § III bajo el apartado 11/I; además Palomar Lapesa (1957), pp. 35s. y LIV, pp. 616s. (3. *wel "sehen, wahrnehmen"); Coelho Ferreira (1986), p. 297 y DBSt (1989).
} 
17) con respecto a la $* n(n)$ geminada, ${ }^{142}$ su conservación en el gen. Elani (que se confronta con el galés elein, elain 'ciervo joven, gamo'), en Elanic(um) y en Elanioca (que tampoco participa en la anticipación de la palatalidad celtibérica en el $n^{\circ}$ 11), frente al desarrollo de -nd- por ultracorrección -es decir como en celtibérico- en Elandus; cf. además el NFam Letondicum, el NInd Aplondus a través de Ablonnos desde la base original Ablon-

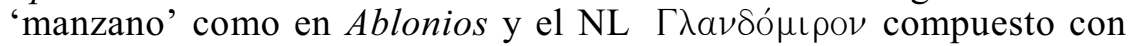
el célt. glano- 'puro' y un segundo elemento del mismo significado;

18) casos de asimilación $m b>m(m)$ frente a su conservación de tipo celtibérico: así en el étnico de los astures Amaci, como resulta de la

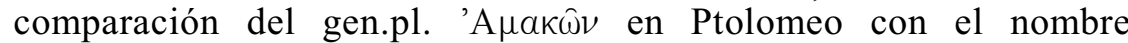
individual *Ambākyos atestiguado en el gen.sg. hispano-celta Ambaici de Iruña. Otros ejemplos podrían ser los topónimos con bases $A m a-$, que se explican mal desde una base tan coloquial como la hipocorística Amma-; la ciudad cántabra de Camarica y los NInd del tipo Camarius frente a la más frecuente base Cambar- como en Cambaricum; quizá el NFam Ammaricum; ${ }^{143}$

19) la variedad de acentuaciones reconstruibles, cf. (i)_Eburánco(n) vs. (ii) Ebureníq(um) desde el mismo NFam *Eburanikōm: ${ }^{144}$

i) un acento, probablemente heredado, en la antepenúltima nos da cuenta también

(a) de la forma típica Cámalos del celta peninsular - presente además en Camalic(um) - desde el original *kámu-lo-s que, procedente de $* k_{m}^{\prime} m H-u-l o-/ \bar{a}$, continúa en el femenino air. cumal y en el galo Camúlus;

(b) del hispánico *kálatos desde el etimológico *káletos 'duro', atestiguados el primero en cib. ka.l.a.to.ku.m que se preserva además en el tipo cib. ka.l.a.i.to.s y hisp.celt. Calaitus, Calaetus (todas las variantes desde el mismo *kalatyo-s), y el segundo y más arcaico reflejado por lo menos en

${ }^{142}$ V. el $\S$ III bajo el apartado 11/II; Albertos Firmat (1966), pp. 112s.; Sánchez Moreno (1996), p. 126; DBSt (1987), p. 163; González Rodríguez (1994), p. 172; Palomar Lapesa (1957), p. 37, Peralta Labrador (2000), p. 96, DBSt (1999), p. 74 y NWÄI, p. 543; Luján (1999/00), pp. 63s. con bibliografía y Delamarre, p. 151.

${ }^{143}$ Los datos en García Alonso (1993/95), pp. 315s. y 390ss.; idem (1999/00), p. 44; Holder: I, 111ss.; las dos agrupaciones familiares en el corpus vetónico ahora en Sánchez Moreno (1996), pp. 121 y 124. Acerca de la posibilidad de reconducir Interamnion y los étnicos derivados al galo Inter ambes v. ya García Alonso (1993/95), p. 302.

${ }^{144}$ González Rodríguez (1986), $\mathrm{n}^{\text {os }} 115$ s. y 117, resp. de Soria y Burgos; eadem 1.c. $\mathrm{n}^{\mathrm{o}} 78$; NWÄI, pp. 450s. y 455, 156 y 454; MLH V/1, p. 150; Albertos Firmat (1974/76), p. 77, y (1966), p. 289; Sánchez Moreno (1996), pp. 123s.; Albertos Firmat (1983), p. 880, y (1975), p. 43; DBSt (1995), p. 25; la etimología arriba al § III/8; González Rodríguez (1986), no 49 y Delamarre, p. 61; Salinas de Frías ( $\left.{ }^{2} 1986\right)$, pp. 71 y 88, Holder: I, 1071, y Marmé (1995), p. 190. La agrupación familiar Be.l.a.i.o.ku.m (¿con caída de -s- intervocálica?) sugiere que también la pareja Ba.l.a.i.s.o.ku.m $\leftarrow$ Balaesus pueda estar relacionada con los *Belaski etc., cf. MLH V/1, p. 60. Erróneas las indicaciones de Untermann en García Merino \& Untermann (2002), p. 138 nota 29, acerca de la acentuación de las lenguas célticas: de las insulares sólo el irlandés conoce un acento inicial, mientras que el britónico comparte con el galo la acentuación de la penúltima sílaba. 
parte por los derivados hispano-célticos del tipo Calet-, más frecuentemente Caled-;

(c) de los sufijos *-lko- y *-rko- (resp. en Bodilcos y Cabarcus) como producto de síncopa.

ii) es un acento, probablemente más moderno, en la penúltima, que nos da cuenta de la asimilación de las vocales pretónicas - además de en Ebureníq(um) - en

(d) BALÁISCAE en Bot. 2, evidentemente procedente de Be.l.a.i.s.ka.z, Be.l.a.i.s.ko.m;

(e) Balatuscun con respecto al Belatu- que se preserva en galo;

(f) Baraeco de * $b^{h}$ er-äk-yo-s con respecto al Comberanea riuus de Liguria y al inber 'river mouth' del irlandés antiguo; $\mathrm{y}$, eventualmente, de la diptongación

(g) en el epíteto de Reve Laráuc[u] 'Boden-' desde la conocida base *plHro- 'fondo'.

Desde la misma perspectiva se pueden considerar otros cuantos cambios fonéticos que - quizá también por ser relativamente tardíossólo se encuentran en el material onomástico céltico peninsular, pero no en celtibérico, y específicamente:

20) la lenición de las oclusivas sordas intervocálicas, que pasan a sonoras, típica entre otros del material onomástico céltico del área lusitana (p.ej. ${ }^{\text {dat }}$ Toudadigoe < *toutat-ikoi, AMIG(UM) en Cantabria, Cludamus 'famosísimo' cerca de León, la Tov́ppira gallega y el sufijo derivacional -ago- frente al -āko- del celtibérico y celta extrahispano): ${ }^{145}$

21) la caída de - $g$ - intervocálica, como resultado final de la lenición (comparable a lo que pasa en galés) en palabras célticas procedentes del territorio lusitano: cf. los ejemplos discutidos junto con la isoglosa $\mathrm{n}^{\mathrm{0}} \mathbf{3}$, a los cuales se añadirán Celtienus, Brialeacui, Turibrie ${ }^{146}$

22) la realización, sin embargo debida a ultracorrección, de las oclusivas sonoras como sordas en una región del suroeste: así, evidentemente, en el э Talabrica de un Límicos y en Turibrice, $\Lambda$ áyкıа, Secovesos, Matuceni y Meducenos; en los personales simples Boutios (frecuente entre los Vettones), Tascus, Toncius así como en Aplondus y Lupiana, que corresponden a los celtas Boudios, Tasgos, Tongios, Ablon- y Lubian-. Cf. además en inicial de palabra

\footnotetext{
${ }^{145}$ Resp. Albertos Firmat (1975), pp. 24 con mapa y 28; DBSt (ZCP 53) con bibliografía; ead. (2000 [2002], p. 184, para la inscripción de Iuliobriga; Luján (1999/00), p. 64. Otro ejemplo en el Caldobenda $<*$ kaleto- de Fuentes de Ropel (Mayer et al. [1998]), mientras que los nombres de la base o con determinante $M e d u$ - 'hidromiel' - pese a unos cuantos mapas y lemas onomásticos donde vienen juntos (como p.ej. en Albertos Firmat [1980/85], p. 287)nada tienen que ver con el tipo Madu- (de *matu- 'bueno $\rightarrow$ oso' como en Matugenus).

${ }^{146}$ Cf. además de la nota 124 arriba, Palomar Lapesa (1957), p. 115; Albertos Firmat (1966), pp. 154 y 302; eadem (1974/76), p. 78; eadem (1975), p. 56; eadem (1980/85), p. 287; eadem (1983), p. 863; Abascal Palazón (1995), p. 39.
} 
$\boldsymbol{P}$ elgus y $_{47}$ Tercinoi en una inscripción ibérica en alfabeto latino del s. II a.C. ;

23) la sonorización de oclusiva sorda inicial de palabra, como en Gadilla $<$ Cadilla o en el genitivo Garici de Caricus $;{ }^{148}$

24) el paso $y>e$ detrás de vocal, cf. Caraeciq $(u m)<* \operatorname{Kar}-\bar{a} k y(o)-i k$ $\bar{o} m$ en área vetona así como -en la teonimia occidentalOcelaecos/a, Roudaecos y Ataecina a lado de Adaegina, con la isoglosa $n^{0} 20$ como el dat. Oenaego. El mismo desarrollo, sin embargo antes de vocal y sin anticipación de palatalidad (como en el $\mathrm{n}^{\mathrm{o}}$ 11) en el topónimo vetón Alea (vs. cib. aila- $<{ }^{*}$ plHi-ā: air. ail 'roca') y el NInd Aleonus entre los Autrigones (a lado de Alionus en otros territorios) $;^{149}$

25) la monoptongación -e- del -ai- contenido en el "nuevo" sufijo -aiko-: cf. -eco- en Tritecu $(m)<*$ Tritaikum <*Tritākyōm en Yecla de Yeltes, a lado de -ego- en los territorios que participan también en la isoglosa $n^{\circ} \mathbf{2 0}$ y de tipo ya romance. ${ }^{150}$

\section{CONCLUSIONES}

Frente a la inadecuación de las hipótesis por medio de las cuales se intenta explicar la compleja celticidad de la Península Ibérica (resp. caps. II y I), hemos visto que el viejo modelo "centro vs. áreas laterales" que Bártoli desarrolló para explicar la dialectología romance (cap. V) puede dar buenos resultados a la hora de explicar la presencia de rasgos a la vez novedosos y arcaicos (capp. III-IV) en el mismo material lingüístico de origen céltico.

Aunque no esté "within the nature of the evidence ever to provide firm answers to these problems" (Cunliffe [ $\left.{ }^{2} 1999\right]$, p. 138), la evidencia disponible nos permite pensar que en origen el celta hispano se haya hablado en varias comunidades de la península hasta el extremo oeste, antes de fortalecerse en un territorio intermedio donde fue desarrollando un aspecto más o menos unitario caracterizado por unos rasgos

${ }^{147}$ Cf. Palomar Lapesa (1957), p. 49ss., 80, 90, 108; Albertos Firmat (1966), p. 302; eadem (1975), p. 33 no 23; eadem (1980/85), pp. 272 y 281s.; Abascal Palazón (1995), p. 91; García Alonso (1999/00), p. 37; MLH II/2, H.3.4. También Aipora por hallarse en este mismo territorio se podría interpretar quizá como forma "desonorizada" de Ebora, pero nótese que de Hoz (1999/00), p. 20 con n. 18 se demuestra escéptico. En este contexto es preciso subrayar que - pese a lo que se lee en unos cuantos repertorios onomásticos, entre otros Palomar Lapesa (1957), pp. 101s. - la escritura de Toncius y sus derivados en lugar de Tongius (derivado del verbo célt. tong- 'jurar') nada tiene que ver con la alternancia apreciable entre p.ej. Tancinus (de la base célt. tanco- 'paz' con el grado cero de la raíz *temk- 'cuajar', DBSt [1987], p. 146) y su forma sonorizada Tanginus.

${ }^{148}$ Palomar Lapesa (1957), pp. 54, 60 y 73.

149 Resp. desde *Ocelaicos/a $<{ }^{*}$ okel-āk-yo-/-ā y ${ }^{*}$ Roudaicos $<*^{*}$ roud ${ }^{h}-\bar{a} k-y o-s$, cf. DBSt (ZCP 53) con bibliografía; Luján (1999/00), pp. 58s.; Prósper (1997), pp. 269s, acerca de “*oin-aiko-” (en realidad *oyn-āk-yo-); Sayas \& López (1991), p. 79; Solana Sainz (1991), p. 175; arriba la nota 44 . La originaria '(Diosa) de la noche' es derivada en -inā desde una base *at-āki-āa *ataica: DBSt op.cit. y NWÄI, p. 80.

${ }^{150}$ Salinas de Frías $\left({ }^{2} 1986\right)$, pp. 55 y 85; Sánchez Moreno (1996), p. 132. Cf. además el listado $\mathrm{n}^{\mathrm{o}} 4$ de Albertos Firmat (1975), p. 27, del cual sin embargo se tendría que excluir por lo menos Cantabrequn, donde -re- representa el desarrollo de *ri típico del celta continental. 
específicos que constituyen las isoglosas distintivas de lo que llamamos celtibérico; y que en las comunidades que se quedaron fuera de la influencia político-cultural del celtibérico hayan podido sobrevivir e incluso desarrollarse, de diferentes formas y durante periodos también diferentes, unos cuantos focos célticos de variada intensidad (cap. VI; cf. la supervivencia de topónimos célticos en comunidades inglesas, es decir al exterior de los territorios tradicionalmente de habla galesa o córnica y también escocesa ${ }^{151}$ ). En particular, a los viejos elementos célticos que se desarrollaron de diferente forma en las diferentes áreas laterales se fueron añadiendo en periodos sucesivos tanto elementos del habla de los celtíberos desplazados a territorios más occidentales como unos elementos del celta del $3 \mathrm{er}$ y $4^{\circ}$ periodo que se había llegado a hablar en el resto del continente, llevados a la Península Ibérica por militares y comerciantes extranjeros.

Por lo tanto, el "(corpus) hispano-celta" definido en el cap. I bajo C resulta compuesto, además de nombres célticos sin rasgos específicos y por eso difícilmente fechables como Toutonos o Tritius, de otros cuatro estratos: i) nombres célticos hispanos antiguos como los compuestos Caturis y Boduoris; ii) nombres celtibéricos verdaderos atestiguados p. ej. en inscripciones latinas como el gen. Ambaici o Anneza (vs. Annedius); iii) nombres célticos arcaicos con desarrollos particulares "extraceltibéricos" como en Catu-enus, Avilio-bris, Boutios; iv) nombres del 3 er y $4^{\circ}$ período céltico como los en -dunum y Mapalia.

En concreto, aunque teniendo en cuenta que con la romanización "Not only was a general onomastic 'landscape' created, which superseded the previous, more local ones, but also the pattern of isoglosses was disturbed", ${ }^{152}$ se han estudiado unas quince isoglosas de innovación en su representación celtibérica, es decir en nuestro caso "central" (cap. III, entre ellas la asimilación $n d>n(n)$ y su ultracorrección $n(n)>n d$ ), para confrontarlas después con $1 \mathrm{a}(\mathrm{s})$ representación(es) "periférica(s)", o sea con la evidencia al respecto del corpus hispano-celta (cap. VII), donde se hallan unos cuantos arcaísmos. Además se han individualizado otras diez innovaciones, aparentemente no compartidas por el área central celtibérica, que pueden haber sido no sólo más tardías sino también específicamente "laterales" (cap. VII).

Se añadirá al margen que unas de las isoglosas que se hallan en el corpus del celta hispánico (central y/o periférico) adelantan las que en forma más desarrollada se encuentran en el ibero-romance (lenición intervocálica, sufijo -iego, anticipación de la palatalidad como en portugués).

\footnotetext{
${ }^{151}$ V. Price (2000), pp. 73ss.

152 de Hoz (1986/88), p. 201; algo más optimistas son Sayas \& López (1991), p. 100 nota 42: "Hay que tener presente que por diversos motivos el dominio romano imprimió una fuerte aceleración a las corrientes migratorias de las personas: y con las personas van sus nombres. Así no es infrecuente ver nombres [...] en lugares donde no es normal encontrarlos. [...] Pero esto no impide ni que las diversas variantes de un nombre sean más frecuentes en una zona que en otra, ni que algunos nombres sean exclusivos, o al menos predominen más en el área lusitanovetona que en la celtibérica, por ejemplo".
} 


\section{BIBLIOGRAFÍA}

ABASCAL PALAZÓN, J. M. (1994): Los nombres personales en las inscripciones latinas de Hispania, (Universidad de) Murcia.

(1995): "Las inscripciones latinas de Santa Lucía del Trampal (Alcuéscar, Cáceres) y el culto de Ataecina en Hispania", Archivo Español de Arqueología 68 (n ${ }^{\text {os }}$ 171-172), pp. 31-105.

(1999): "Apuntes epigráficos", Archivo Español de Arqueología $72\left(\mathrm{n}^{\text {os }} 179-180\right)$, pp. 287-298.

AlBertos Firmat, M ${ }^{\mathrm{a}}$ L. (1966): La onomástica personal primitiva de Hispania Tarraconense y Bética, C.S.I.C., Salamanca.

(1974/76): "La antroponimia prerromana de la Península Ibérica", Actas del I Coloquio sobre lenguas y culturas prerromanas de la Península Ibérica (Salamanca 1974), eds. F. Jordá \& L. Michelena, pp. 57-86, (Universidad de) Salamanca 1976.

(1975): Organizaciones suprafamiliares en la Hispania antigua = Studia archaeologica 37, Valladolid.

(1976/79): "La onomástica de la Celtiberia", Actas del II Coloquio sobre lenguas y culturas prerromanas de la Península Ibérica (Tübingen 1976), eds. A. Tovar, M. Faust, F. Fischer, M. Koch, pp. 131-167, (Universidad de) Salamanca 1979.

(1980/85): "La onomástica personal indígena del noroeste peninsular (astures y galaicos)", Actas del III Coloquio sobre lenguas y culturas paleohispánicas (Lisboa 1980), ed. J. de Hoz, pp. 255-310, (Universidad de) Salamanca 1985.

(1983): "Onomastique personelle indigène de la Péninsule Ibérique sous la domination romaine", Aufstieg und Niedergang der römischen Welt, Teil II: Principat, Band 29: Sprache und Literatur, ed. (H. Temporini y) W. Haase, 2. Teilband, pp. 853-892, W. de Gruyter, Berlín y New York.

(1990): "Los topónimos en -briga en Hispania", Veleia 7, pp. 131-146.

Almagro GorbeA, M. (1991): "Los celtas en la Península Ibérica", Los celtas en la Península Ibérica = Revista de Arqueología s./n., eds. idem y J.A. García Castro, pp. 12-17, Zugarto ediciones, Madrid.

(1993): "Los Celtas en la Península Ibérica: origen y personalidad cultural", Los Celtas: Hispania y Europa, eds. idem y G. Ruiz Zapatero, pp. 121-173, Editorial Actas, Madrid.

(2001): "Los celtas en la Península Ibérica", Celtas y Vettones, eds. idem, M. Mariné y, J.R. Álvarez Sanchís, pp. 95-113, (Diputación Provincial de) Ávila.

Almagro GorbeA, M. \& DÁVIlA, A. F. (1995): “El área superficial de los oppida en la Hispania 'Céltica'", Complutum 6, pp. 209-233.

Almagro [GorbeA], M. et alii (2001): Protohistoria de la Península Ibérica, Ariel, Barcelona.

Álvarez SAnchís, J. R. (1999): Los Vettones, Real Academia de la Historia, Madrid..

ARENAS ESTEBAN, J. A. (1998/99a): "Presentación", Actas de los Encuentros sobre "El origen del mundo celtibérico" (Molina de 
Centro y áreas laterales: la formación del celtibérico...

Aragón, 1-3 de Octubre de 1998), eds. J.A. Arenas Esteban y M ${ }^{\mathrm{a}} \mathrm{V}$. Palacios Tamayo, pp. 7-9, (Ayuntamiento de) Molina de Aragón 1999.

(1998/99b): "El inicio de la Edad del Hierro en el sector central del Sistema Ibérico", Actas de los Encuentros sobre "El origen del mundo celtibérico" (Molina de Aragón, 1-3 de Octubre de 1998), eds. idem y $\mathrm{M}^{\mathrm{a}} \mathrm{V}$. Palacios Tamayo, pp. 191- 211, (Ayuntamiento de) Molina de Aragón 1999.

(en prensa): "Die Kelten in Hispanien: Schlüssel zu ihrer Identifikation und Probleme des archäologischen Befundes", Veleia 18-19.

Arenas Esteban, J. A. \& Martínez Naranjo, J. P. (1999): "El origen de la cultura celtibérica", Revista de Soria 25 = Celtíberos: Homenaje a J.L. Argente, pp. 19-28.

Arenas [Esteban], J.A. \& De Bernardo Stempel, P., González [RODRÍGUEZ], $\mathrm{M}^{\mathrm{A}} \mathrm{C}$. Y GORROCHATEGUI, J. (2002): "La estela de Retugenos (K.12.1) y el imperativo celtibérico", Emérita 19 (2001), pp. 307-318.

BARTOLI, M. (1945): Saggi di linguistica spaziale, R. Università di Torino: Fondo di studi Parini-Chirio, Torino.

BELTRÁN LlORIS, F., ed. (1996): El tercer bronce de Botorrita (Contrebia Belaisca), Gobierno de Aragón, Zaragoza [entre otros con contribuciones del mismo, de J. DE HOZ y de J. UNTERMANN].

BELTRÁN LlORIS, F. (1999): "Writing, Language and Society: Iberians, Celts and Romans in Northeastern Spain in the 2nd \& 1st Centuries BC", Bulletin of the Institute of Classical Studies 43, pp. 131-151.

Billy = BILLY, P.-H., Thesaurus Linguae Gallicae, Olms, Hildesheim, Zürich y New York 1993.

BosCH-GIMPERA, P. (1950-1956): "Les mouvements celtiques - essai de reconstitution", Études celtiques 5/1950-51, pp. 352-400; 6/195354, pp. 71-126 y 328-355; 7/1955-56, pp. 147-181.

( 1995$)$ : El poblamiento antiguo y la formación de los pueblos de España, (Universidad Nacional Autónoma de) México (1 ${ }^{\mathrm{a}}$ ed. 1945).

Búa CARBALlo, J.C. \& Silva, S. L. (1994/95): "Los topónimos gallegos en -bre de origen prerromano", BNF 29/30, pp. 13-41.

Burillo Mozota, F. (1998): Los celtíberos: etnías y estados, G. Mondadori, Barcelona.

CAMPANILE, E. (1999): Saggi di linguistica comparativa e ricostruzione culturale, eds. M.P. Bologna, F. Motta y Ch. Orlandi, Istituti editoriali e Poligrafici internazionali, Pisa y Roma.

CAPAlvo, Á. (1996): Celtiberia: Un estudio de fuentes literarias antiguas, Institución "Fernándo el Católico", Zaragoza.

CIPRÉS, P. (1999): "El impacto de los celtas en la Península Ibérica según Estrabón", Estrabón e Iberia: Nuevas Perspectivas de Estudio, ed. G. Cruz Andreotti, pp. 121-151, Málaga.

Coelho Ferreira DA Silva, A. (1986): A cultura castreja no Noroeste de Portugal, Cámara Municipal de Paços de Ferreira y Museu Arqueológico da Citânia de Sanfins. 
Correa, J. A. (1989): "Posibles antropónimos en las inscripciones en escritura del SO. (o tartesia)", Veleia 6, pp. 243-252.

(1993): "Antropónimos galos y ligures en inscripciones ibéricas", Studia Palaeohispanica et Indogermanica J. Untermann ab amicis Hispanicis oblata, pp. 101-116, (Universitat de) Barcelona.

(1994/96): "La epigrafía del Sudoeste: Estado de la cuestión”, La Hispania prerromana $=$ Actas del VI Coloquio sobre lenguas $y$ culturas prerromanas de la Península Ibérica (Coimbra, octubre de 1994), eds. F. Villar y J. d'Encarnação, pp. 65-75, Ediciones Universidad, Salamanca.

Coseriu, E. ( $\left.{ }^{2} 1979\right)$ : Die Sprachgeographie, Gunter Narr, Tubinga (trad. alem. de La geografía linguística, Montevideo 1956).

Cunliffe, B. ( $\left.{ }^{2} 1999\right):$ The ancient Celts, Penguin, Londres $\left(1^{\mathrm{a}}\right.$ ed. Oxford 1997).

DE BERNARDO STEMPEL, P. (1987): Die Vertretung der indogermanischen liquiden und nasalen Sonanten im Keltischen, IBS 54, Innsbruck.

(1989): “A Welsh Cognate for Gaul. $\alpha$ vooovvv $\alpha \beta$ ?", Bulletin of the Board of Celtic Studies 36, pp. 102-105.

(1991): "Die Sprache altbritannischer Münzlegenden", Zeitschrift für celtische Philologie 44, pp. 36-55.

(1992/93): "Probleme der relativen Chronologie: nochmals zu idg. *ō im Keltischen", Akten des ersten Symposiums deutschsprachiger Keltologen (Gosen bei Berlin 1992), eds. M. Rockel y St. Zimmer, pp. 37-56, Max Niemeyer, Tubinga.

(1993/96): "Die Stummvokale: eine Bilanz für das Keltiberische, Die größeren altkeltischen Sprachdenkmäler: Akten des Kolloquiums Innsbruck (April-Mai 1993), eds. W. Meid y P. Anreiter, pp. 212-256, IBK Sonderheft 95, Innsbruck 1996.

(1994a): "Das indogermanische $m(V) n o$-Verbaladjektiv im Keltischen", Indogermanica et Caucasica: FS für Karl Horst Schmidt, eds. R. Bielmeier y R. Stempel (con la colaboración de R. Lanszweert), pp. 281-305, W. de Gruyter, Berlin y New York.

(1994b): "Rudolf Thurneysen (1857-1940) und sein sprachwissenschaftliches Werk", Zeitschrift für celtische Philologie 46, pp. 216-248.

(1995): "Gaulish Accentuation. Results and outlook", HispanoGallo-Brittonica: FS D.E. Evans, eds. J.F. Eska, R.G. Gruffydd y N. Jacobs, pp. 16-32, University of Wales Press, Cardiff.

(1996a): "Il celtiberico Pi.n.Ti.ś come antico composto indoeuropeo", Études Celtiques 32, pp. 117-124.

(1996b): "Tratti linguistici comuni ad appellativi e toponimi di origine celtica in Italia", Studia ex hilaritate: Mélanges de linguistique sardes et romanes offerts à M. H.J. Wolf $=$ Travaux de Linguistique et de Philologie 33/34, eds. D. Kremer y A. Monjour, pp. 109-136, Estrasburgo, Nancy y Paris.

(1998): "Minima Celtica zwischen Sprach- und Kulturgeschichte: 1. Zum Namen der Kelten im Westen; 2. 'Zinn' 
und andere Entlehnungen im Bereich de Metallterminologie; 3. Der Wagentyp carpentum; 4. nochmals zu gall. cantalon (R.I.G-L-9), Man and the Animal World = Studies in Archaeozoology, Archaeology, Anthropology and Palaeolinguistics in memoriam S. Bökönyi, eds. P. Anreiter, L. Bartosiewicz, E. Jerem y W. Meid, pp. 601-610, Archaeolingua (Vol. 8), Budapest.

(1998a): "Le declinazioni nel celtico continentale: innovazioni comuni al gallico e al goidelico?", Gaulois et Celtique continental (Clermont-Ferrand, 13-16 mai 1998), eds. P.-Y. Lambert y G.-J. Pinault, Paris.

(1998b): "Sull'origine delle sibilanti in celtiberico: una modifica alla teoria di Francisco Villar", Gaulois et Celtique continental (Clermont-Ferrand, 13-16 mai 1998), eds. P.-Y. Lambert y G.-J. Pinault, Paris.

(1999): "Zur Methode der Wortbildungsanalyse von Korpussprachen (anhand keltischen Materials)", Studia Celtica et Indogermanica $=$ Festschrift für $W$. Meid, eds. P. Anreiter y E. Jerem, pp. 61-77, Archaeolingua (Vol. 10), Budapest.

(1999/e.p.): "From Indo-European to the individual Celtic languages" [Comunicación ante el XIth ICCS en Cork 1999], 3rd FS Gearóid Mac Eoin, eds. D. Ó hAodha y D.P. Ó Baoill, Four Courts Press, Dublín.

(1999/01): "Grafemica e fonologia del celtiberico: 1. Nuovi dati sulle vocali mute; 2 . Una nuova legge fonetica che genera dittonghi; 3. Fonti e fasi di sviluppo della sibilante sonora", Religión, lengua $y$ cultura prerromanas de Hispania $=$ Actas del $8^{\circ}$ Coloquio sobre lenguas y culturas prerromanas de la Península Ibérica (Salamanca, Mayo de 1999), eds. F. Villar y M ${ }^{a}$ P. Fernández Álvarez, pp. 319-334, Ediciones Universidad, Salamanca.

(2000): "Keltische Ortsnamen", HOOPS' Reallexikon der Germanischen Altertumskunde, vol. 16, pp. 407-413, W. de Gruyter, Berlín y New York, 2000.

(2001): "Gotisch IN-WEITIP gup und gallisch ANDE-díon UEEDIIU-mi (Chamalières, Z. 1)", Historische Sprachforschung 114, pp. 164-170.

(2001/e.p.): "Der Beitrag des Keltischen zur Rekonstruktion des indogermanischen Nomens", Akten der Arbeitstagung zum indogermanischen Nomen (Freiburg/Br., September 2001).

(2000 [2002]): "Celtib. karvo gortika 'favor amicitiae', rita 'ofrecida', monima 'recuerdo' y los formularios de las inscripciones celtibéricas", Veleia 17 (2000), pp. 183-189.

(2000/e.p.): "Die sprachliche Analyse keltischer Theonyme", Zeitschrift für celtische Philologie 53/2002.

Degavre = DEGAVRE, J., Lexique gaulois, Vols. I-II, Mémoires de la Société Belge d'Études Celtiques 9 y 10, Bruselas 1998.

Delamarre = DelamARRE, X., Dictionnaire de la langue gauloise: Une approche linguistique du vieux-celtique continental, Errance, Paris 2001.

DE LA RÚA, C. (1995): "La historia del poblamiento del País Vasco desde una perspectiva antropológica", Muntanyes i població: El 
passat dels Pirineus des d'una perspectiva multidisciplinâria, eds. J. Bertranpetit y E. Vives, pp. 301-316, Centre de Trobada de les Cultures Pirenenques, (Govern d') Andorra.

Die Iberer = AA.VV., Catálogo de la Exposición en la Kunst- und Ausstellungshalle der Bundesrepublik Deutschland, Bonn (JanuarApril 1998), 1997/1998.

DIL $=($ Contributions to a $)$ Dictionary of the Irish Language, Royal Irish Academy, Dublin, 1913-1976.

ESKA, J. F. (1989): Towards an Interpretation of the Hispano-Celtic Inscription of Botorrita, IBS 59, Innsbruck.

(1995): “Two Notes on Phonology in Continental Celtic", Studia Celtica Japonica (New Series) 7, pp. 9-19.

(1994): "Rethinking the Evolution of Celtic Constituent Configuration", Münchener Studien zur Sprachwissenschaft 55, pp. 7-39.

Evans, D. E. (1976/79): "On the Celticity of Some Hispanic Personal Names", Actas del II Coloquio sobre lenguas y culturas prerromanas de la Península Ibérica (Tübingen 1976), eds. A. Tovar, M. Faust, F. Fischer, M. Koch, pp. 117-129, (Universidad de) Salamanca 1979.

FALKNER, M. (1948): "Die norischen Personennamen auf $-u$ und ihre kulturgeschichtliche Bedeutung", Frühgeschichte und Sprachwissen-schaft, pp. 39-54, Gerold \& Co., Viena.

FATÁs, G. (1980): Contrebia Belaisca (Botorrita, Zaragoza), II: Tabula Contrebiensis, (Universidad de) Zaragoza.

García Alonso, J. L. (1993/95): La Geografía de Claudio Ptolomeo y la Península Ibérica (Diss. Salamanca en microfichas).

(1999/00): "On the Celticity of the Duero Plateau: Place-Names in Ptolemy", Ptolemy: towards a linguistic atlas of the earliest Celtic place-names of Europe $=$ Papers from a workshop, sponsored by the British Academy (Aberystwyth 1999), eds. D.N. Parsons y P. Sims-Williams, pp. 29-53, CMCS, Aberystwyth.

GARCÍA-BELlidO, M ${ }^{\mathrm{A}}$ P. (1997): "Coinage and ethnicity in Celtic Spain", Zeitschrift für celtische Philologie 49-50, pp. 219-242.

GARcía MERINO, C. \& UnTERMAnN, J. (2002): "Revisión de la lectura de la tessera Uxamensis y valoración de las téseras en el contexto de la configuración del poblamiento celtibérico en el siglo I a.C.”, Boletín del Seminario de estudios de arte y arqueología 65/1999, pp. 133-152.

GOI = THURNEYSEN, R., A Grammar of Old Irish, D.I.A.S, Dublin 1946 (Reimpr. 1975).

GómEZ-PANTOJA, J. (1994/96): "Gentilidad y origen", La Hispania prerromana $=$ Actas del VI Coloquio sobre lenguas y culturas prerromanas de la Península Ibérica (Coimbra, octubre de 1994), eds. F. Villar y J. d'Encarnação, pp. 77-100, Ediciones Universidad, Salamanca 1996.

GÓNZALEZ RODRÍGUEZ, Ma C. (1986): Las unidades organizativas indígenas del área indoeuropea de Hispania, Anejo $\mathrm{n}^{\mathrm{o}} 2$ de Veleia, Vitoria-Gasteiz. 
(1994): "Las unidades organizativas indígenas II: Addenda et corrigenda", Veleia 11, 169-175.

GorRochATEGUI, J. (1985/87): "En torno a la clasificación del lusitano", Actas del IV Coloquio sobre lenguas y culturas paleohispánicas, eds. idem, J.L. Melena y J. Santos, Veleia 2-3, pp. 7791.

(1990): "Consideraciones sobre la fórmula onomástica y la expresión del origen en algunos textos celtibéricos menores", Studia Indogermanica et Palaeohispanica in honorem A. Tovar et L. Michelena, ed. F. Villar, pp. 291-312, (Universidad de) Salamanca.

(1993): "Onomástica Indígena de Aquitania: adiciones y correcciones I", Sprachen und Schriften des antiken Mittelmeerraums: FS für Jürgen Untermann, eds. F. Heidermanns, H. Rix y E. Seebold, pp. 145-155, IBS 78, Innsbruck.

(1994): "La lengua de las poblaciones prerromanas del área indoeuropea", Las estructuras sociales indigenas del norte de la Península Ibérica, eds. $\mathrm{M}^{\mathrm{a}}$ C. González y J. Santos, pp. 13-21, Universidad del País Vasco, Vitoria-Gasteiz.

(1999/00): "Ptolemy's Aquitania and the Ebro Valley", Ptolemy: towards a linguistic atlas of the earliest Celtic place-names of Europe = Papers from a workshop, sponsored by the British Academy (Aberystwyth 1999), eds. D.N. Parsons y P. SimsWilliams, pp. 143-157, CMCS, Aberystwyth.

(2001): "La lengua celtibérica", Celtas y Vettones, eds. M. Almagro Gorbea, M. Mariné y J.R. Álvarez Sanchís, pp. 201-207, (Diputación Provincial de) Ávila.

GrÜNEWALD, TH. (2000): “Kelten: II. Historisches”, HOOPS' Reallexikon der Germanischen Altertumskunde, eds. H. Beck, D. Geuenich y H. Steuer (con R. Müller), Bd. 16, pp. 372-388, Walter de Gruyter, Berlin \& New York.

HAWKES, CH. (1971/73): "Cumulative Celticity' in Pre-Roman Britain”, Études Celtiques $13(2)=$ Actes du $4^{\text {ème }}$ Congrès international d'études celtiques (Rennes, juillet 1971), vol. II, pp. 607-628.

HERNÁNDEZ VERA, J.A. \& NúÑEZ MARCEN, J. (1989): "Un nuevo antropónimo indígena, sobre cerámica, procedente de Graccurris", Veleia 6, pp. 207-214.

Holder = HOLDER, A., Alt-celtischer Sprachschatz, Vols. I-III, Graz 1961-1962 (Reimpr. de la ed. de Lipsia 1896-1907).

DE Hoz, J. (1986/88): "Hispano-Celtic and Celtiberian", Proceedings of the First North American Congress of Celtic Studies, ed. G.W. MacLennan, pp. 191-207, (University of) Ottawa.

(1989/93): "La lengua y la escritura ibéricas, y las lenguas de los íberos", Lengua y cultura en la Hispania prerromana = Actas del V Coloquio sobre lenguas y culturas prerromanas de la Península Ibérica (Colonia, Noviembre de 1989), eds. J. Untermann y F. Villar, pp. 635-666, Ediciones Universidad, Salamanca.

(1991/92): "Lepontic, Celtiberian, Gaulish and the archaeological evidence", Études Celtiques $29=$ Actes du IX 
Congrès international d'études celtiques (Paris, juillet 1991), $2^{\text {ème }}$ partie, pp. 223-240.

(1992): "The Celts of the Iberian Peninsula", Zeitschrift für celtische Philologie 45, pp. 1-37.

(1993): "Las sociedades paleohispánicas del área no indoeuropea y la escritura", Archivo Español de Arqueología 66 (N. $\left.{ }^{\text {os }} 167-168\right)$, pp. 3-29.

(1994): "Castellum Aviliobris. Los celtas del extremo occidente continental", Indogermanica et Caucasica: FS für Karl Horst Schmidt, eds. R. Bielmeier y R. Stempel (con la colaboración de R. Lanszweert), pp. 348-362, W. de Gruyter, Berlin y New York.

(1995a): "Notas sobre nuevas y viejas leyendas monetales", La moneda hispánica: ciudad y territorio, eds. $\mathrm{M}^{\mathrm{a}} \mathrm{P}$. García-Bellido y R.M. Sobral Centeno, pp. 317-324, Anejos de ArchEspArq 14, Madrid.

(1995b): "El poblamiento antiguo de los Pirineos desde el punto de vista lingüístico", Muntanyes i població: El passat dels Pirineus des d'una perspectiva multidisciplinâria, eds. J. Bertranpetit y E. Vives, pp. 271-299, Centre de Trobada de les Cultures Pirenenques, (Govern d') Andorra.

(1996/97): "Las lenguas célticas de la antigüedad en su contexto etnohistórico", Celtas y Celtíberos: Realidad o leyenda = Actas de las jornadas celebradas en la Universidad Complutense de Madrid del 27 de febrero al 8 de marzo de 1996, pp. 52-63, Unión Cultural Arqueológica, Madrid.

(1997/99): "Identité-différenciation au travers des témoignages linguistiques et alphabétiques: le monde celtique et ibère", Confini e frontiera nella Grecità d'Occidente $=$ Atti del $37^{\circ}$ convegno di studi sulla Magna Grecia (Taranto, ottobre 1997), pp. 213-246, Arte tipografica, Napoli.

(1999): "Did a *brigantinos exist in Continental Celtic?", Studia Celtica et Indogermanica $=$ Festschrift für W. Meid, eds. P. Anreiter y E. Jerem, pp. 145-149, Archaeolingua (Vol. 10), Budapest.

(1999/00): "From Ptolemy to the Ethnic and Linguistic Reality: The Case of South-Western Spain and Portugal", Ptolemy: towards a linguistic atlas of the earliest Celtic place-names of Europe = Papers from a workshop, sponsored by the British Academy (Aberystwyth 1999), eds. D.N. Parsons y P. Sims-Williams, pp. 1128, CMCS, Aberystwyth.

IRMN = CASTILlo, C. \& Gómez-PANTOJA, J. \& MAuleón, Ma D. Inscripciones romanas del Museo de Navarra, Diputación Foral de Navarra, Pamplona 1981.

JORDÁN CÓLERA, C. (1998): Introducción al celtibérico, (Universidad de) Zaragoza.

KALB, PH. (1990): "Zum Keltenbegriff in der Archäologie der Iberischen Halbinsel", Madrider Mitteilungen 31, pp. 338-347.

KGPN = SCHMIDT, K. H., Die Komposition in gallischen Personennamen, Max Niemyer, Tubinga 1957. 
KocH, J. T. (1992): “'Gallo-Brittonic' vs. 'Insular Celtic': The Interrelationships of the Celtic Languages Reconsidered", Bretagne et pays celtiques: langues, histoire, civilisation $=$ Mélanges offerts à la mémoire de L. Fleuriot, eds. G. Le Menn y J.-I. Le Moing, pp. 471-495, Skol y Presses Universitaires, Saint-Brieuc y Rennes.

LAMBERT, P.-Y. (1990): reseña de "M.Lejeune, R.I.G. II/1, 1988, 45" supplément a Gallia", Études Celtiques 27, pp. 381-383.

LEIA = VENDRYES, J. \& BACHELlery, E. \& LAMBERT, P.-Y., Lexique étymologique de l'irlandais ancien, D.I.A.S \& C.N.R.S, Dublín y París 1959ss.

LIV = RIX, H. ET ALII, Lexikon der indogermanischen Verben: die Wurzeln und ihre Primärstammbildungen, Reichert, Wiesbaden 1998.

LOCHNER VON HÜTTENBACH, F. (1989): Die römerzeitlichen Personennamen der Steiermark: Herkunft und Auswertung, Leykam, Graz.

LORRIO, A. J. (1997): Los celtíberos, (Universidad Complutense y Universidad de) Alicante.

(2001): "Los celtíberos", Celtas y Vettones, eds. M. Almagro Gorbea, M. Mariné y J.R. Álvarez Sanchís, pp. 183-199, (Diputación Provincial de) Ávila.

LUJÁN [MARTÍNEZ], E. R. (1996): "La onomástica celtibérica: actualización y aspectos comparativos", Veleia 13, pp. 199-217.

(1999/00): "Ptolemy's Callaecia and the Language(s) of the Callaeci", Ptolemy: towards a linguistic atlas of the earliest Celtic place-names of Europe $=$ Papers from a workshop, sponsored by the British Academy (Aberystwyth 1999), eds. D.N. Parsons y P. SimsWilliams, pp. 55-72, CMCS, Aberystwyth.

MACKillop, J. (1998): Dictionary of Celtic Mythology, Oxford.

MARCO SimÓN, F. (1994): "Reflexiones sobre el hecho religioso en el contexto social de la Celtiberia", Las estructuras sociales indígenas del norte de la Península Ibérica, eds. $\mathrm{M}^{\mathrm{a}} \mathrm{C}$. González y J. Santos, pp. 35-50, Universidad del País Vasco, Vitoria-Gasteiz.

(1996): “¿Volcas en Hispania?: a propósito de Livio, 21, 19, 6", Études Celtiques 32, pp. 49-55.

MARMÉ, U. (1995): Die Verbalkomposition im Altirischen (unter besonderer Berücksichtigung des Präfixes frühgoid. *uts-), Dissertation der Universität Bonn.

MARTín BRAVO, A. Ma (1999): Los orígenes de Lusitania: el I milenio a.C. en la Alta Extremadura, Real Academia de la Historia, Madrid.

MAYER, M. \& GARCÍA, R. \& ABÁSOlO, J.A. (1998): "El bronce de Fuentes de Ropel (Zamora)", Boletín del Seminario de estudios de arte y arqueología 64, pp. 161-174.

Medrano MARqués, M. \& DíAZ SANZ, Ma A. (2000): "Novedades acerca de las ciudades celtas de Contrebia Belaisca y Nertobriga", Salduie 1, pp. 165-180.

MeID, W. (2000): "Forschungsbericht Altkeltische Sprachen: 3. Keltiberisch", Kratylos 45, pp. 1-28. 
MLH = UNTERMANN, J., Monumenta Linguarum Hispanicarum, Reichert, Wiesbaden, vols. I-III, IV (con la colaboración de D. WODTKO), V/1 (WODTKO, DAGMAR S., Wörterbuch der keltiberischen Inschriften), 1975-2000.

Moralejo, J. J. (en prensa): "Gallaecia y sus etimologías", Homenaje M. Díaz, pp. 1-23, (Universidad de) Santiago.

NWÄI = DE BERNARDO STEMPEL, P., Nominale Wortbildung des älteren Irischen: Stammbildung und Derivation, Max Niemeyer, Buchreihe der ZCP 15, Tubinga 1999.

OPEL = Onomasticon Provinciarum Europae Latinarum, eds. LÖRINCZ, B. \& Redö, F. ex materia ab A. MóCSY, R. Feldmann, E. MARTON et M. SzILÁGYI collecta, vols. I-III: A- Pythea, Budapest (Archaeolingua 3) 1994 y Viena (Forschungsgesellschaft Wiener Stadtarchäologie) 1999-2000.

PALOMAR LAPESA, M. (1957): La onomástica personal pre-latina de la antigua Lusitania, C.S.I.C., Salamanca.

PEDRERO SANCHO, R. (1997/99): “Aproximación lingüística al teónimo lusitano-gallego Bandue/Bandi”, Pueblos, lenguas y escrituras en la Hispania prerromana $=$ Actas del VII Coloquio sobre lenguas y culturas paleohispánicas (Zaragoza, Marzo de 1997), eds. F. Villar y F. Beltrán, pp. 535-543, Ediciones Universidad, Salamanca.

Peralta LABRADOR, E. (2000): Los cántabros antes de Roma, Real Academia de la Historia, Madrid.

POKORNY, J. (1936-1940): "Urgeschichte der Kelten und Illyrier", Zeitschrift für celtische Philologie 20/1936, pp. 315-352 y 490-522; 21/1940, pp. 55-166.

PopŁAWsKI, P. A. (2000): "Indo-European $*_{s}$ in Celtiberian", Studia Indogermanica Lodziensia 3/1999 = Studies in honour of Ignacy Ryszard Danka, eds. P. Stalmaszczyk y K.T. Witczak, pp. 11-20, Łódź.

PrósPer, B. Ma (1997): "La divinidad paleo-hispana Cossue/Coso y el dios itálico Cōnsus", $A I \Omega N$ (Sezione linguistica) 19, pp. 267-302.

(en prensa): "A Celtic dedicatory formula from the Callaecia Bracarensis: Ariounis Mincosegaegis".

RIB = COllingwood, R.G. \& Wright, R.P., con S.S. Frere, M. ROXAN y R.S.O. TOMLIN, The Roman Inscriptions of Britain, vols. I-II, Alan Sutton ${ }^{2} 1995$.

Rowland, R.J.JR. (1994/95): “Caturo, not Caturon(i?)us”, Beiträge zur Namenforschung 29/30, pp. 355-357.

RUBiO ORECILla, F.J. (1999): “Aproximación lingüística al bronce de Torrijo (Teruel)", Veleia 16, pp. 137-157.

RUIZ ZAPATERO, G. (1995): "El poblamiento del primer milenio a.C. en los Pirineos", Muntanyes i població: El passat dels Pirineus des d'una perspectiva multidisciplinâria, eds. J. Bertranpetit y E. Vives, pp. 85-101, Centre de Trobada de les Cultures Pirenenques, (Govern d') Andorra.

RUIZ ZAPATERO, G. \& LORRIO, A. J. (1998/99): "Las raíces prehistorícas del mundo celtibérico", Actas de los Encuentros sobre "El origen del mundo celtibérico" (Molina de Aragón, 1-3 de Octubre de 
1998), eds. J.A. Arenas Esteban y $\mathrm{M}^{\mathrm{a}}$ V. Palacios Tamayo, pp. 21 36, (Ayuntamiento de) Molina de Aragón 1999.

SALINAS DE FRIAS, M. ( $\left.{ }^{2} 1986\right)$ : La organización tribal de los Vettones (Pueblos prerromanos de Salamanca), Salamanca.

SÁNCHEZ MoReno, E. (1996): “A propósito de las gentilitates: los grupos familiares del área vetona y su adecuación para la interpretación de la organización social prerromana", Veleia 13, pp. 115-142.

Santos Yanguas, J. \& Hoces de La Guardia Bermejo, A. L. (1989): "Inscripciones romanas de Segovia. I: Inscripciones inéditas", Veleia 6, pp. 215-234.

Sayas Abengoechea, J. J. \& López Melero, R. (1991): "Vettones", Las entitades étnicas de la Meseta norte de Hispania en época

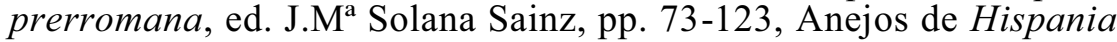
Antiqua, (Universidad de) Valladolid.

SCHMIDT, K. H. (1980/85): "A Contribution to the Identification of Lusitanian", Actas del III Coloquio sobre lenguas y culturas paleohispánicas, ed. J. de Hoz, pp. 319-341, Ediciones Universidad, Salamanca.

(1992), "Problems of Celtiberian", Studia Celtica Japonica (New Series) 5, pp. 37-75.

(1999/01): "The Contribution of Celtiberian to the Reconstruction of Common Celtic: Instalment II", Religión, lengua y cultura prerromanas de Hispania $=$ Actas del $8^{\circ}$ Coloquio sobre lenguas y culturas prerromanas de la Península Ibérica (Salamanca, Mayo 1999), eds. F. Villar y Mª P. Fernández Álvarez, pp. 595-611, Ediciones Universidad, Salamanca.

SiLES, J. (1976/79): "Über die Sibilanten in iberischer Schrift", Actas del II Coloquio sobre lenguas y culturas prerromanas de la Península Ibérica (Tübingen 1976), eds. A. Tovar, M. Faust, F. Fischer y M. Koch, pp. 81-99, (Universidad de) Salamanca.

Solana SAINZ, J. M (1991): “Autrigones”, Las entitades étnicas de la Meseta norte de Hispania en época prerromana, ed. idem, pp. 159191, Anejos de Hispania Antiqua, (Universidad de) Valladolid.

Tovar, A. (1950): "Pre-Indoeuropeans, Pre-Celts, and Celts in the Hispanic Peninsula", The Journal of Celtic Studies 1, pp. 11-23.

(1977): "El nombre de Celtas en Hispania", Homenaje a García Bellido vol. III = Revista de la Universidad Complutense 26 (109), pp. 163-178.

UNTERMANN, J. (1980/85): “Los teónimos de la región lusitano-gallega como fuente de las lenguas indígenas", Actas del III Coloquio sobre lenguas y culturas paleohispánicas (Lisboa 1980), ed. J. de Hoz, pp. 343-363, (Universidad de) Salamanca 1985.

(1991/95): "Lengua y poblamiento prerromano en el territorio celtibérico", III Simposio sobre los celtíberos: Poblamiento celtibérico, ed. F. Burillo Mozota, pp. 7-24, Institución "Fernando el Católico", Zaragoza. 
(2000): "Lenguas y escrituras entorno a Tartessos", Argantonio, Rey de Tartessos, ed. C. Aranegui Gascó, pp. 68-77, Consorci de Museus de la Comunitat Valenciana, Valencia.

(2001): Die vorrömischen Sprachen der iberischen Halbinsel: Wege und Aporien bei ihrer Entzifferung, Nordrhein-Westfälische Akademie der Wissenschaften: Vorträge-G 375, Westdeutscher Verlag, Wiesbaden.

VelazA FRÍAS, J. (1996): Epigrafía y lengua ibéricas, Arco Libros, Madrid.

VILLAR, F. (1999): "Hispanocelta o Celtibérico", Language Change and Typological Variation: In Honor of Winfried P. Lehmann, Vol. I: Language Change and Phonology, eds. E.C. Polomé y C.F. Justus, pp. 60-77, Journal of Indo-European Studies, Monograph 30.

(2001): "La lengua de los celtas y otros pueblos indoeuropeos de la Península Ibérica", Celtas y Vettones, eds. idem, M. Mariné y J.R. Álvarez Sanchís, pp. 115-121, (Diputación Provincial de) Ávila.

VILLAR, F. \& ARBOLEDAS, P. (1999): "Sabora y el tratamiento de la /s/

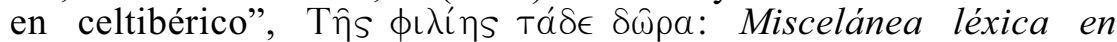
memoria de Conchita Serrano, pp. 427-435, Manuales y Anejos de Emerita 41, CSIC, Madrid.

Villar, F. \& DíAz, Ma A., Medrano, M. Ma y Jordán Cólera, C. (2001): El IV bronce de Botorrita (Contrebia Belaisca): Arqueología y lingüística, Ediciones Universidad, Salamanca.

WAtKIns, C. (1999): "Two Celtic Notes", Studia Celtica et Indogermanica $=$ Festschrift für W. Meid, eds. P. Anreiter y E. Jerem, pp. 539-543, Archaeolingua (Vol. 10), Budapest.

Patrizia de Bernardo Stempel

Universidad del País Vasco

e-mail:ecpdestp@vc.ehu.es 